\title{
Single-Site Heterogeneous Catalysts ${ }^{\dagger}$
}

\author{
John Meurig Thomas ${ }^{a, b^{*}}$ Robert Raja $^{c}$ and Dewi W. Lewis ${ }^{d}$
}

[**] Prof. Sir J.M. Thomas, The Royal Institution of Great Britain, Davy Faraday Research Laboratory, 21 Albemarle Street, London W1S 4BS (UK). Department of Materials Science and Metallurgy, New Museums Site, Pembroke Street, Cambridge CB2 3QZ (UK). Tel: +44-1223334467, Fax: +44-1223 740360. E-mail: jmt@ri.ac.uk; Dr. R. Raja, Department of Chemistry, University of Cambridge, Lensfield Road, Cambridge CB2 1EW (UK). Tel: +44-1223-336335, Fax: +44-1223-336017. E-mail: robert@ri.ac.uk; Dr. D.W. Lewis, Department of Chemistry, University College London, 20 Gordon Street, London WC1H 0AJ. Tel: +44-207-6794779, Fax: +44-207-6797463. E-mail: d.w.lewis@ucl.ac.uk.

\begin{abstract}
Intellectually, the advantages that flow from the availability of single-site heterogeneous catalysts (SSHC) are many. Firstly, they facilitate the determination of the kinetics and mechanism of catalytic turnover - both experimentally and computationally - and render accessible the energetics of various intermediates (including short-lived transition states). These facts in turn offer a rational strategic principle for the design of new catalysts and the improvement of existing ones. Secondly, it is generally possible to prepare soluble molecular fragments that circumscribe the single-site, thus enabling a direct comparison to be made, experimentally, between the catalytic performance of the same active site when functioning as a heterogeneous (continuous solid) as well as a homogeneous (dispersed molecular) catalyst. This also makes it possible to modify the immediate atomic environment as well as the central atomic structure of the active site. From the practical standpoint, SSHC exhibit very high selectivities leading to the production of sharply defined molecular products, just as do their homogeneous analogues.

Examples are given of (i) the high regioselectivities of inorganic SSHC enzyme mimics which oxyfunctionalize terminal methyl groups in linear alkanes under mild conditions; (ii) the marked shape-selectivity of SSHC in converting methanol (by Brönsted-acid catalyzed dehydration) preferentially to ethene and propene; (iii) numerous selective hydrogenations with high turnover frequencies (under solvent-free conditions) of polyenes, and also of several enantioselective hydrogenations characterized by high values of $e e$; and (iv) bifunctional openstructure forms of SSHC in which 'isolated' acid centers and 'isolated' redox centers cooperatively lead to the in situ production of hydroxylamine (from $\mathrm{NH}_{3}$ and $\mathrm{O}_{2}$ ), cyclohexanoneoxime (from cyclohexanone) and (-caprolactam (the precursor to nylon-6). Given that mesoporous silicas with very large internal surface areas are ideal supports for SSHC, and that more than a quarter of the elements of the Periodic Table may be grafted as active sites onto such silicas, there is abundant scope here for creating new catalytic opportunities.
\end{abstract}




\section{Table of Contents}

1. Introduction

2. Four Principal Categories of SSHC

3. Individual Isolated Ions, Atoms, Molecular Complexes and Bimetallic Clusters as Single-Site Heterogeneous Catalysts

4. Single-Site Heterogeneous Organometallic Chiral Catalysts

5. Single-Site, "Ship-in-Bottle" Catalysts (zeozymes)

6. Single-Site, Open-Structure Solid Catalysts

7. A Selection of Examples Illustrating Practical Applications of SSHC

8. Envoi

\section{Introduction}

It is often explicitly stated, but far more frequently implied, that solid catalysts functioning heterogeneously possess a spectrum of active sites each with their own energetics, activity and selectivity. The plausibility of this statement is re-inforced if one examines the topography of a metal surface such as that depicted in Figure 1. Here atoms located at surface steps or kinks are stereochemically different from one another and less fully coordinated to other atoms than those at terrace sites and flat exterior surfaces. ${ }^{[1]}$ But even at a flat exterior surface (typically the (111) face of an f.c.c. metal such as platinum), there are clearly three distinct adsorption sites - atop, bridge and hollow - for small molecules such as carbon monoxide to be bound. It is not surprising, therefore, that the enthalpy of adsorption as a function of surface coverage falls, and that a temperature-programmed desorption has several peaks, as these reflect the variety of energetic situations associated with the adsorbed species. ${ }^{[2]}$ This is a situation that is encountered with all metal and alloy catalysts and with a very large number of other catalysts that are continuous solids, including close-packed oxides, halides and chalcogenides.

(Figure 1 here)

Yet, the concept of the catalytically active site, introduced ${ }^{[3]}$ to the literature of catalysis by H.S. Taylor eighty years ago, is as widely used as ever; and it has, inter alia, spawned other, heuristically and practically, important notions such as 'active site engineering' and 'active site modification.' Demonstrably, it is easy to comprehend what is meant by the structurally welldefined active site of a metalloenzyme (or any other enzyme) and also by the active site of members of the entire family of homogeneous (i.e. molecular) catalysts in which discrete molecular entities (encompassing the active site) are dispersed in a fluid phase, usually water. No intellectual or practical problems are encountered when one starts referring to these catalysts as 
being of the 'single-site' variety.

So far as heterogeneous catalysts made of metal or alloy are concerned, the nature of the active sites is far less sharply defined than was originally envisaged by Taylor. Taylor advanced reasons for believing that preferential adsorption on a catalyst surface would take place at those atoms situated at peaks, fissures and other crystalline discontinuities. (In Taylor's days the concepts of kinks, emergent dislocations and even point-defects had not yet been formulated). Moreover, he inferred that such atoms would also have the highest catalytic activity. In the intervening years it has become clear that preferential adsorption does indeed occur (see Figure 1) at the step and kink sites of solid surfaces. But what one requires in a good, catalytically active site is not a high binding energy; rather one of an intermediate value which is such that it optimises both the residence time of the adsorbate and facilitates its conversion into desirable product species.

If one is concerned with strictly stoichiometric processes (rather than catalytic ones) such as adsorption per se or with surface reactions in a non-catalytic sense, such as thermal oxidation, decomposition, dissolution or gasification, crystalline discontinuities do indeed exhibit enhanced reactivity, and in that context may legitimately be regarded as active centers. ${ }^{4]}$ Somorjai's and others ${ }^{[5]}$ work have shown that surface steps and kinks on many metals may indeed function as favoured sites for the activation of $\mathrm{C}(\mathrm{H}, \mathrm{H}(\mathrm{H}, \mathrm{O}=\mathrm{O}, \mathrm{N}$ ?N, or $\mathrm{C}$ ? O bonds under certain circumstances. A major advance in the notion of catalytically active centres in inorganic solids came with the Cossee(Arlman interpretation of Ziegler(Natta catalysts. ${ }^{6]}$ Working on the plausible assumption that the prismatic faces of $\left(\left(\mathrm{TiCl}_{3}\right.\right.$, a vital constituent of such catalysts, inevitably - for thermodynamic reasons - contain a minute fraction of chloride ion vacancies and hence coordinatively unsaturated Ti ions, Cossee and Arlman showed that these ions are the active centres for the stereoregular polymerisation of alkenes. But, for metals and alloys, it has become abundantly clear, thanks to the investigations of Ertl et al, ${ }^{[7,8]}$ and others, that a great deal of surface mobility (even fluidity) exists under quite thermally mild catalytic conditions. Standingwave patterns and periodic kinetic oscillations in the oxidation of $\mathrm{CO}$ on a $\mathrm{Pt}$ surface are pronounced; ${ }^{[9]}$ and chaotic phenomena involving spatio-temporal changes on quite rapid timescales are frequent occurrences, as are pronounced surface morphological changes brought about as the surface catalytic reactions proceed. ${ }^{[10]}$ It is therefore clear that, at such catalyst surfaces unlike the situations that prevail for solids in categories A to D in Table 1 (below) - the concept of a structurally fixed active site is of little value. For such catalysts it is more fruitful to picture them as energetically (and otherwise) multi-site catalysts. But where, in other kinds of solid catalysts, one, or a small number of, metal atom(s) is firmly and uniformly anchored to a support (see category A) the concept of a single-site catalyst is certainly valid.

There appears, therefore, to be a dichotomy - an ostensible contradiction of facts. On the one hand, it is profitable, for certain types of solid catalysts, to retain the notion of the active site; on the other, the idea of a well-defined active site at a metal surface (where they were conceived by Taylor) seems to be progressively less valid.[11] One of the principal purposes of this article is to resolve this apparent contradiction. More importantly, it is to identify and classify numerous examples of single-site heterogeneous catalysts - henceforth referred to as SSHC - as they are already playing a significant role in many industrially-important chemical processes and are evermore present in a variety of academic (laboratory-based) situations. Many new developments (and Patents) are continuing to emerge in this hitherto inadequately recognized branch of heterogeneous catalysis. Moreover, single-site heterogeneous catalysts (SSHC) are important for two other reasons which are of profound significance so far as the understanding of the nature of 
catalysis as well as the design of new catalysts is concerned. First, sophisticated and reliable theoretical computations of the structures, energetics and kinetics of catalytic conversions may readily be performed on transformations that take place at single-sites, and these, in turn, enable quantitative comparisons to be made between homogeneous and heterogeneous catalysts involving essentially the same active centres. Second, equipped with such quantitative information it becomes possible to evolve strategic principles for the design of improved catalysts. In other catalytic situations, notably catalysis by metals and most continuous solids, because of the perceived complexity of their mode of action, certain design possibilities cannot even be framed, let alone be constructively implemented.

To fix our ideas, it is prudent to elaborate briefly at this point what we mean by a 'singlesite' in the general context of heterogeneous (solid) catalysts. The 'single-site' (catalytically active center) may consist of one or more atoms - as will become clear in the discussion and examples given below. Such single sites are spatially isolated from one another - there is no spectroscopic or other cross-talk between such sites. Each site has the same energy of interaction between it and a reactant as every other single-site; and each such site is structurally wellcharacterized, just as the single sites in homogeneous molecular catalysts are.

By identifying the reality and usefulness of categorizing certain kinds of solid catalysts as SSHCs, a rational strategic principle for the design of new catalysts clearly emerges. Much progress has been made in the design of such catalysts in the past few years. The so-called "uniform heterogeneous catalysts" reviewed ${ }^{[12]}$ by one of us in 1988 - where active sites are spatially distributed inside open-structure solids and freely accessible to reactants - will be seen below to be a special case of the SSHC discussed herein.

(Table 1 here)

\section{Four Principal Categories of SSHC}

Table 1 enumerates the four main categories into which SSHC may be conveniently classified. As we shall see below, there are subdivisions within some of these categories. For example, in category A, various kinds of supports, to which the catalytic entity containing the single-site are attached, may confer extra activity or selectivity to the SSHC. And both monofunctional and bifunctional catalytic performance may be exhibited by certain examples in category $D$.

In all four categories there exist structurally well-defined active sites, the precise atomic nature of which may be probed - increasingly nowadays under reaction conditions, ${ }^{[13,14]}$ - by a range of experimental and computational techniques. Such sites are amenable (by pre- or postsynthesis interruption) to controllable, subtle changes in structure that may have far-reaching catalytic repercussions.

3. Individual Isolated Ions, Atoms, Molecular Complexes and Bimetallic Clusters as SingleSite Heterogeneous Catalysts

In these four sub-categories we distinguish quite distinct features. First, there are transition-metal-ions grafted on to high-area supports, silica being the most suitable and popular, thereby forming a kind of metal-oxo entity. Second, single atoms of a metal such as palladium may be anchored to a surface structural defect at an oxide support, typically magnesia. Third, isolated 
organometallic complexes anchored to silica or alumina surfaces also function as single-site catalysts. Finally, we may have small clusters (all of the same size) of metal atoms or of bimetallic clusters or of their carbides anchored securely to mesoporous silica also exhibiting single-site but multinuclear behaviour.

\subsection{Single-Site Transition Metal Ions Supported on Mesoporous Silica}

From the early days of heterogeneous catalysis, silica has been widely used as a support. Its merits are numerous: it is robust, readily prepared (with high surface area), it does not swell in contact with organic solvents, it has considerable thermal stability as well as structural flexibility and it bonds rather readily to a large number of the elements of the Periodic Table. Moreover, soluble analogues of silica, the so-called silsesquioxanes ${ }^{[15,16]}$ (see, for example, Figure 2) are available, so that it becomes readily possible fully to characterize new functionalities that are attached to silica surfaces. In addition, the catalytic performance of a hetero ion (e.g. $\mathrm{Ti}, \mathrm{Fe}, \mathrm{Cr}$, etc, active site) introduced to a silica may be studied both as a homogeneous and as a heterogeneous catalyst. ${ }^{[17]}$

\section{(Figure 2 here)}

Twenty five years ago Basset et al, ${ }^{[18]}$ extending the earlier studies of others, ${ }^{[19]}$ began a systematic study, which has continued to blossom ${ }^{[20]}$ in which they deliberately set out to functionalise the surfaces of the so-called Aerosil silicas which are non-porous. Their work, often described as surface organometallic chemistry, produces SSHC by appropriately functionalising the residual pendant silanol groups $(? \mathrm{SiOH})$ on the Aerosil silica (surface area typically 200 $\mathrm{m}^{2} \mathrm{~g}^{-1}$ and silanol surface concentration of 0.7 ( 0.2 per $\mathrm{nm}^{2}$, which is equivalent to $0.23 \mathrm{~mol} \mathrm{OH}$ $\left.\mathrm{g}^{-1}\right)$. A specific example is the tripodally grafted zirconium hydride, which activates alkanes under mild conditions (Figure 3). Other transition metal ions have been grafted on to silica by Basset et al; and their work on grafted organometallic complexes as SSHC, is returned to again below.

\section{(Figure 3 here)}

Great scope for the preparation of a variety of single-ion SSHC began once it became readily possible - thanks to discoveries at the Mobil Oil Co. ${ }^{[21]}$ and in Japan (Waseda University and the Toyota Co.) ${ }^{[22]}$ - to prepare mesoporous silica with pore-diameters that may controllably fall in the range 20 to $100 \AA$ or more. Later workers produced mesoporous silicas with pore diameters as large as $500 \AA$. Such silicas possess exceptionally high surface areas (typically 600 to $1000 \mathrm{~m}^{2} \mathrm{~g}^{-1}$ ) and their inner and outer surfaces possess a profusion of pendant silanol groups (Figure 4), approximately 1 to 2 per $\mathrm{nm}^{2}$.

\section{(Figure 4 here)}

Corma, ${ }^{[23]}$ Thomas ${ }^{[24,25]}$ and others ${ }^{[26]}$ were quick to appreciate the advantages that large-pore silicas would confer in facilitating the preparation of single-site, ion-centred heterogeneous catalysts. A significant advance was made when $\mathrm{Ti}^{\mathrm{IV}}$ active centres were grafted on to the inner walls of mesoporous silica using an organometallic precursor, in particular titanocene dichloride $\left[\mathrm{Ti}(\mathrm{Cp})_{2} \mathrm{Cl}_{2}\right]$ as was done by Maschmeyer et al. ${ }^{[27]}$ The key steps in the introduction of the isolated, single-site active centres on the inner walls of the so-called MCM-41 silica are shown in Figure 5. The detailed course of this 'heterogenization' of a Ti ${ }^{\mathrm{IV}}$ active centre was followed by in situ X-ray absorption spectroscopy combined with in situ X-ray diffractometry. ${ }^{[28]} \mathrm{DFT}$ calculations yield important supplementary information: in particular they show that the titanyl 
group $(>\mathrm{Ti}=\mathrm{O})$, once postulated ${ }^{[29]}$ as the active site for epoxidation of alkenes, is energetically unfavourable.

\section{(Figure 5 here)}

It is to be seen that a tripodally-grafted $\mathrm{Ti}(\mathrm{OH})$ group constitutes the isolated active site, very resistant to leaching, in this instance. Note that the van der Waals envelopes (see Figure 6) of the cyclopentadienyl groups attached to the surface bound ("half-sandwich") intermediate, shown in Figure 5, ensure that no two $\mathrm{Ti}^{\mathrm{IV}}$ active centres are closer than $c a 7 \AA$, thereby ensuring the generation of a genuine, isolated, single-site catalyst. (Other methods of introducing $\mathrm{Ti}^{\mathrm{IV}}$ active centres, involving salts of titanium or in-grown titanium alkoxide additives to the siliceous precursor do not guarantee production of isolated, tetrahedral $\mathrm{Ti}^{\mathrm{IV}}$ centres and a tendency to form $\mathrm{Ti}(\mathrm{O}$ (Ti linkages exists with these methods). It is an exceptionally good epoxidation catalyst using alkyl hydroperoxides as we shall describe later.

\section{(Figure 6 here)}

Other transition-metal ions may be grafted on to mesoporous silicas using the metallocene route, and active centres composed of isolated $\mathrm{Mo}^{\mathrm{VI}}, \mathrm{Cr}^{\mathrm{VI}}$ and $\mathrm{VO}^{\mathrm{IV}}$ have been described. ${ }^{[30,31]}$

An altogether different, but equally effective approach has been pioneered by Tilley et $a l^{[32-35]}$ in which a molecular precursor is taken to yield a series of active catalysts on mesoporous (and certain other) supports. The metal ions in question are those of $\mathrm{Ti}, \mathrm{Cr}, \mathrm{Fe}$ and vanadyl; and the essence of their preparation is that the desired atomic environment aimed at in the final catalyst (e.g. $\mathrm{Ti}\left((\mathrm{OSi})_{4}\right.$ or $\mathrm{Ti}\left((\mathrm{OSi})_{3}\right.$ is already present in the thermolytic precursor. Thus, by taking ( $\mathrm{PrO}) \mathrm{Ti}\left[\mathrm{OSi}\left(\mathrm{O}^{\mathrm{t}} \mathrm{Bu}\right)_{3}\right]_{3}$, the tris(tert-butoxy)siloxy titanium complex, the environment ultimately achieved in the single-site catalyst is $\operatorname{Ti}\left((\mathrm{OSi})_{3}\right.$, and from $\mathrm{Ti}\left[\mathrm{OSi}\left(\mathrm{O}^{\mathrm{t}} \mathrm{Bu}\right)_{3}\right]_{4}$ it is $\mathrm{Ti}\left((\mathrm{OSi})_{4}\right.$. Typical supports used by Tilley were the high-area mesoporous silicas MCM-41 and SBA-15, the latter being distinctly more thermally stable than the former. The general picture, depicting the production of this type of SSHC is shown in Figure 7. The precursor is bonded to the hydroxyl groups of the surface of the silica via protonolysis reactions (lower half of Figure 7). For the case of an alkoxy (siloxy) species of the type M[OSi $\left.\left(\mathrm{O}^{t} \mathrm{Bu}\right)_{3}\right]_{\mathrm{n}}$, where $\mathrm{M}$ ( $\mathrm{Ti}, \mathrm{Fe}, \mathrm{Cr}, \ldots$ this surface-attachment chemistry occurs with loss of $\mathrm{HO}^{\mathrm{t}} \mathrm{Bu}$ or $\mathrm{HOSi}\left(\mathrm{O}^{\mathrm{t} B u}\right)_{3}$, to result in bonding to the surface through $\mathrm{M}(\mathrm{O}(($ surface $)$ or $\mathrm{Si}(\mathrm{O}($ (surface $)$ linkages, respectively. (Calcination results in the loss of all the carbon and hydrogen, leading to the single-site catalyst of nominal composition $\mathrm{MO}_{\mathrm{x}}(\mathrm{n}-1) \mathrm{SiO}_{2}$. All the physical methods of analysis, such as DRUV and EPR carried out on the product signifies that the metal-ion sites (such as Fe ${ }^{\mathrm{III}}$ sites) possess distorted tetrahedral geometry. When attempts are made to prepare isolated $\mathrm{Fe}$ III sites using $\mathrm{FeCl}_{3}, \mathrm{FePO}_{4}$ or $\mathrm{Fe}_{2}\left(\mathrm{SO}_{4}\right)_{3}$ as precursors no success is achieved and calcination almost invariably leads to clusters of iron oxides). Isolated $\mathrm{Cu}^{\mathrm{I}}$ species, which are good catalysts for the production of dimethyl carbonate from methanol and $\mathrm{CO}_{2}$, ${ }^{34 \mathrm{~b}]}$ may be formed on silica using $\left[\mathrm{CuOSi}\left(\mathrm{O}^{\mathrm{t} B u}\right)_{3}\right]_{4}$ as precursor.

\section{(Figure 7 here)}

\subsection{Supported Isolated Atoms as Single-Site Heterogeneous Catalysts}

Recent experimental work has established beyond doubt that a single metal atom of palladium, supported on magnesia $(\mathrm{MgO})$ facilitates the cyclotrimerization of acetylene ${ }^{[36]}$ and the oxidation of $\mathrm{CO}$ by $\mathrm{O}_{2}$ to $\mathrm{CO}_{2}{ }^{[37]}$ Heiz and coworkers, ${ }^{[36,37]}$ using mass-selected techniques, prepared singlesite active centres such as that shown in Figure 8, in which an F-centre (i.e. an electron trapped at an oxygen anion vacancy) in $\mathrm{MgO}$ localizes a single $\mathrm{Pd}$ atom, with electronic charge being transferred to the Pd. 
(Figure 8 here)

When this 'single-atom' active site is first exposed to $\mathrm{O}_{2}$ and then to $\mathrm{CO}$ (at $90 \mathrm{~K}$ ) and then subjected to a linear temperature rise, conversion ensues, the adsorbed gases combine to yield $\mathrm{CO}_{2}$, and the surplus oxygen is taken up by the F-center, which thereby loses its ability to localize the $\mathrm{Pd}$. Ab initio computations reveal the optimised structure of the $\mathrm{MgO}$ $\mathrm{Pd}(\mathrm{CO})_{2} \mathrm{O}_{2}$ single-site active center with its bound reactants (Figure 9). Heiz et al ${ }^{[36]}$ have also completed an experimental-cum-computational study of this model, single atom version of a SSHC in the case of the cyclotrimerization of acetylene to benzene. In each of these examples of SSHC it is to be noted that, because of the elimination of the F-center during reaction in the first case and the clustering of the $\mathrm{Pd}$ atoms to form larger units $\left(\mathrm{Pd}_{\mathrm{n}}, 3<\mathrm{n}<30\right)$ in the second, there is no sustained catalytic turnover. In a sense, therefore, this admirable model study, like many in the literature, is concerned with a surface stoichiometric rather than a catalytic reaction.

\section{(Figure 9 here)}

\subsection{Anchored Organometallic Complexes as SSHC}

Using the surface organometallic approach, Basset et al ${ }^{[20]}$ have produced a number of single-site catalysts at non-porous silica surfaces, the molecular complexes thereby anchored being fully characterized by both spectroscopic and chemical methods. Figure 10 shows the single-sites for three powerful examples of metathesis reactions. Basset's group, and especially that of Marks ${ }^{[38-40]}$ (see below), have also produced single-site, heterogeneous catalysts derived from metallocenes for the polymerisation of alkenes.

(Figure 10 here)

Microcrystalline (- $\mathrm{TiCl}_{3}$ Ziegler-Natta catalysts, because they have several non-identical atomic environments around the catalytically active centers - the chloride ion vacancy may be a regular site or at a step or corner sites - yield polymers with broad molecular-weight distributions. Homogeneous metallocene catalysts, on the other hand yield highly uniform homopolymers and co-polymers; and this arises because of the identical coordination environment of the active site in the homogeneous metallocene catalyst. If the metallocene-type polymerisation catalysts could be so anchored as to have only a single kind of active site, this would unite the best qualities of the homogeneous and heterogeneous agents. Recent work, which we now briefly describe, has achieved this desirable goal.

Take first the work of Marks et al, ${ }^{[38-40]}$ who have used a variety of oxidic supports. Partially dehydroxylated alumina has $c a 4$ Brönsted acidic $\mathrm{OH}$ groups, $c a 5.5$ Lewis acidic $\mathrm{Al}^{\mathrm{III}}$ centres and $c a 5.5$ Lewis basic oxide centres per $\mathrm{nm}^{2}$ of surface area. The fully dehydroxylated alumina has a much lower Brönsted acidic surface concentration ( $c a 0.12)$, though the concentrations of the other centres remain essentially the same. An even more strongly acidic surface is that of the so-called "superacidic sulphated zirconia." (Recent evidence suggests that this surface is not "superacidic"). When a zirconocene of general formula $\mathrm{L}_{\mathrm{n}} \mathrm{ZrR}_{2}$ ( $\mathrm{L}$ ( a cyclopentadienyl ligand, and R an alkyl group) approaches the "superacidic" surface, a cationiclike-structure as schematised below, forms:

This, in effect, is an ion pair consisting of a cationic metallocene and a weak conjugate base of a strong Brönsted acid site. Here, the negative charge of the conjugate base is so highly delocalised 
that coordination to the single-site cationic $\mathrm{Zr}$ centre is minimal, thereby facilitating access of the alkene to the active site.

Marks et $a l^{[40]}$ have elucidated other, related single-site organometallic electrophiles on "superacidic" sulphated zirconia, including $\left(\mathrm{C}_{\mathrm{p}}\right)_{2} \mathrm{Th}\left(\mathrm{CH}_{3}\right)_{2}$ and $\mathrm{C}_{\mathrm{p}} \mathrm{Ti}\left(\mathrm{CH}_{3}\right)_{2}$, where $\mathrm{C}_{\mathrm{p}}=$ $\left({ }^{5}-\mathrm{C}_{5} \mathrm{H}_{5}\right.$ and $\mathrm{C}_{\mathrm{p}}=\left({ }^{5}\left(\mathrm{CH}_{3}\right)_{5} \mathrm{C}_{5}\right.$. And on sulphated alumina, they have shown that protonolysis at the strong surface Brönsted $(\mathrm{OH})$ acidic site again yields a "cation-like" highly reactive (in polymerisation) zirconocenium electrophile $\left(\mathrm{C}_{\mathrm{p}}\right)_{2} \mathrm{ZrCH}_{3}{ }^{+}$. On a dehydroxylated silica surface no such "cation-like" single-site active centre is formed.

Finally, a recent elegant paper by McKittrick and Jones ${ }^{[41]}$ discloses a general method for preparing an isolated titanium-centred polymerisation catalyst on porous silica. The essence of the preparation is shown in the following schemes:

(Schemes 1 and 2 here)

The catalytic performance of the final, site-isolated heterogeneous Ti-centred polymerisation catalyst (designated (8) in Scheme 2) exceeds that of even the homogeneous analogue.

\subsubsection{Single-Site Organometallic Complexes Anchored by Non-Covalent Interaction}

In addition to immobilising single-site molecular catalysts to solid surfaces by covalent bonding (as done by McKittrick and Jones), ${ }^{[41]}$ it is also feasible, and indeed more convenient, to do so by non-covalent means. Bianchini et $a l^{[42]}$ and we ${ }^{[31,43-45]}$ have taken advantage of the strong hydrogen bonding that secures tripodal attachment of an ionic (or zwitterionic) complex to a silanol rich silica surface via a triflate ${ }^{[46]}$ or a sulphonate tail. ${ }^{[42]}$

The grafted $\mathrm{Rh}(\mathrm{I})$ catalyst, (Sulfos) $\mathrm{Rh}(\mathrm{COD})$, on silica is an example of SSHC where it hydrogenates alkenes (in either flow reactors or batch reactors) in hydrocarbon solvents. It also hydroformylates alkenes such as hex-1-ene under solid-liquid conditions. When, however the hydroformylation takes place under solid-gas conditions, the syngas $\left(\mathrm{CO}+\mathrm{H}_{2}\right)$ converts the active catalyst into an inactive one (Figure 11, right) where a dicarbonyl derivative is formed $\left\{(\operatorname{sulfos}) \mathrm{Rh}(\mathrm{CO})_{2}\right\}{ }^{[42]}$ de Rege et all46] have also taken advantage of the hydrogen bonding of a triflate group to secure the active complex to a silica support.

\section{(Figure 11 here)}

\subsection{Individual, Isolated, Bimetallic Clusters as Single-Site Heterogeneous Catalysts}

Along with our colleagues, B.F.G. Johnson et al ${ }^{[47-50]}$ we have shown that monodisperse mixedmetal cluster carbonylates may be uniformly incorporated inside mesoporous silica and gently decarbonylated to yield the naked clusters, which are anchored securely to the underlying silica (Figure 12). The key point here is to recognise that the method of preparation produces:

i) clusters that are of the same stoichiometry and size (monodisperse),

ii) a spatially uniform distribution of the clusters on the inner walls of the high-area mesoporous supports.

\section{(Figure 12 here)}

These statements are supported by non-destructive electron tomographic studies of Thomas, Midgley and co-workers - see Figure 13 - where virtual "slices" of the mesoporous silica support are depicted.[51,52] Typically, the size of these clusters falls in the range of ca 0.5 to $0.8 \mathrm{~nm}$, depending on their precise stoichiometry. They are so small that essentially, all the atoms within each cluster is effectively a 'surface' one. These nanoparticle bimetallic catalysts display very 
high activities in hydrogenation processes (of many kinds), and are also highly selective.

(Figure 13 here)

A number of important, potentially commercial examples, especially in the context of solvent-free processes is given in the examples (see Section 7). Turnover frequencies associated with $\mathrm{Pd}_{6} \mathrm{Ru}_{6}$ nanoclusters in the hydrogenation of a typical alkene exceed by an order of magnitude those for monoelemental Pd or $\mathrm{Ru}$ clusters. ${ }^{[48]}$ The structures of these nanoparticle bimetallic clusters are determined (usually under in situ catalytic conditions) by X-ray absorption spectroscopy. Two examples are shown in Figure 14.

\section{(Figure 14 here)}

Insofar as the reasons for the synergy in catalytic effect between two metals in a bimetallic, nanoparticle cluster is concerned, it is not yet clear what the precise mechanism is. In qualitative terms we know that $\mathrm{Ru}$ is effective in activating molecular hydrogen and that $\mathrm{Pd}$ readily activates an olefinic bond. Furthermore, the recent work of Adams et al ${ }^{[53,54]}$ sheds some light on this general question. In their study of Pt-Ru carbonyl clusters, they found explicit evidence that $\mathrm{Pt}-\mathrm{Ru}$ bonds are directly implicated in catalytic hydrogenations (of alkynes such as substituted acetylenes). Density functional (DFT) calculations, which have already elucidated the detailed structure of mixed-metal cluster carbides such as $\mathrm{Cu}_{4} \mathrm{C}_{2} \mathrm{Ru}_{12}$ (see Figure 14), should in future be able to estimate how many molecules of a particular reactant may be simultaneously catalytically converted at a single cluster. (It is relevant to note that in the work of Heiz et al ${ }^{[36,37]}$ quoted above on the cyclotrimerization of acetylene on $\operatorname{Pd}_{\mathrm{n}}$ clusters, only one molecule of benzene is liberated (in a temperature programmed reaction) from a supported single-site entity consisting of 1, 2 or 3 atoms of $\mathrm{Pd}$, but two benzene molecules are liberated in clusters of either $4,5,6$ or 7 atoms of $\mathrm{Pd})$.

Although not all the atoms in the bimetallic cluster nanoparticles are geometrically equivalent (see Figure 14), nevertheless there is prima facie evidence (which needs to be tested further) that the multi-nuclear bimetallic entities seem to behave as a single-site catalyst in the sense defined in Section 1 above. (This is reminiscent of some metallo-enzymes where several metal ions are situated at the singlesite, catalytically active center).

\section{Single-Site Heterogeneous Organometallic Chiral Catalysts}

In a comprehensive analysis of the feasibility of effecting enantioselective hydrogenation of prochiral reactants, the German worker H. Brunner ${ }^{[55]}$ stated

that "the limited success of heterogeneous catalysts in enantioselective reactions is due to the fact that on the surface of a heterogeneous catalyst there are many different catalytically active centres. Each of these centres has its own selectivity and the total selectivity is usually low." This statement, made in 1996, echoes our introductory remarks in this article. But since 1996 great progress has been made (recently partly reviewed in a special issue of Topics in Catalysis) ${ }^{[56]}$ in developing good, efficient and highly effective SSHC for chiral conversions.

First, we recall the relevant background work on non-chiral conversions using immobilized organometallic catalysts (such as the metallocenes used in homogeneous solution) see Marks, ${ }^{[38-40]}$ Bianchini ${ }^{[42]}$ and Jones et al. ${ }^{[57]}$ In all these cases we have single-site heterogeneous reactions (polymerisations, hydrogenations and hydroformylations). We also note 
the work of Hutchings ${ }^{[58]}$ who, by modifying zeolite-Y with chiral molecules (such as 1,3-dithiane 1 oxide) achieved an efficient chiral preference in the catalytic dehydration of racemic butan-2-ol. We shall see, in Section 7, how a single-site chiral CrIII-Salen complex anchored to a silica surface is an effective enantioselective catalyst in the asymmetric ring opening of epoxides..59]

It is therefore clearly established that single-site heterogeneous chiral catalysts, involving immobilized organometallic (or enantiomeric organic) species are viable propositions. We now show that, using mesoporous silica supports, high-performance single-site heterogeneous chiral catalysts may be conveniently prepared following methods that we have described ${ }^{[43-45,57]}$ fully elsewhere, but which are summarized below. (The drive to prepare enantiomerically pure products for the pharmaceutical, agrochemical and related industries, such as flavours and fragrances, is partly a response to tightening legislation, but it also reflects an attempt to develop efficient, recyclable catalysts such as SSHCs).

We have shown repeatedly that, with mesoporous silica either of the highly ordered (but thermally fragile kind e.g. MCM-41 and SBA-15) or non-ordered desiccant-grade commercially available (Davison) silica and robust type ${ }^{[44]}$ each of which have pendant silanol groups, a range of sizeable chiral metal complexes and organometallic moieties may be tethered to the inner walls of the silica. This is done using either alkylhalides, amines, carboxylates or phosphanes. The procedure to arrive at single-site, well-isolated asymmetric organometallic active centres on the inner walls only of the mesoporous silica is outlined ${ }^{49]}$ in Figure 15, where we render the exterior surfaces 'neutral' in the sense that the dichloro-diphenyl silane, which functionalises all the silanols at the exterior surfaces, is used under conditions where it cannot diffuse to the interior.

(Figures 15 here)

Silanols at the interior surfaces are functionalized using trichlorosilane propyl bromide, the ensuing reactions (Figure 16) to tether the chiral organometallic entities being effected via the bromine atom.

\section{(Figure 16 here)}

When certain kinds of organometallic, chiral catalysts are tethered to the inner walls of the mesoporous silica, it follows that the reactant's (substrate) interaction with both the pore walls and the chiral directing group will be distinct from the interaction it would experience if the chiral catalysts were free (as in the case of a homogeneous catalyst). The confinement of the reactant within the mesopore will lead to a larger influence of the chiral directing group on the orientation of the substrate relative to the reactive catalytic centre when compared with the situation in solution. The validity of this strategic principle has been multiply attested in our laboratories ${ }^{[4,57]}$ - see, for example, our work on allylic amination ${ }^{[60]}$ (of cinnamyl acetate and benzylamine) and on several instances of hydrogenation, ${ }^{[44,61]}$ - and specific examples are cited later.

The reality of how tethering an asymmetric catalyst at a concave surface boosts the resulting enantioselectivity is summarized in Figure 17, where the results of a particular hydrogenation (of methyl benzoylformate to methyl mandelate - see Scheme 3) are compared for the same catalyst $\left(\mathrm{Rh}^{(\mathrm{I})}-(\mathrm{S})-(-)-2\right.$-aminomethyl-1-ethyl pyrrolidine) tethered in the one case on a concave, and in another on a convex silica.

\section{(Figure 17 and Schemes 3 here)}

It is clear that the catalytic performance is enhanced using a concave silica support. We have also shown ${ }^{[44]}$ that non-covalent attachment of the asymmetric catalyst as shown in Figure 18 (i.e. using hydrogen-bonding and not covalent bonding) in the manner of Bianchini et all42] and de Rege et ${ }^{\left[{ }^{[46]}\right.}$ is an effective method of generating well-defined, isolated and readily accessible 
single-site active centers for chiral conversions.

\section{(Figure 18 here)}

The convenience of using non-covalently tethered chiral organometallic catalysts in the production of fine chemicals and pharmaceuticals has obvious practical merit.[62]

\section{Single-Site, "Ship-in-Bottle" Catalysts}

\section{Zeolitic supports for so-called "ship-in-bottle" catalysts of the types used by} Herron, ${ }^{[63]}$ Raja Ratnasamy and Vasudevan, ${ }^{[64-66]}$ Bäckvall[67] and Jacobs ${ }^{[68]}$ and exemplified in Figure 19 have long been entertained as being important in situations where it is necessary to prevent an active site entity, such as a metalloporphyrin or metal-molecular complex, from losing its intrinsic catalytic performance because of dimerization or other complicating side-reactions. Such encapsulated catalysts, which are single-site, also allow access of only those reactant molecules small enough to diffuse through the windows of the zeolitic cage, and prevent any of those products, which, if formed, are too large, from leaving the reaction environment. In general, however, it is preservation of the single-site (isolated state) catalytic activity that is of paramount importance.

\section{(Figure 19 here)}

These catalysts, frequently termed zeozymes or enzyme mimics for obvious reasons, have yielded encouraging and patentable results in oxyfunctionalizing methane to methanol ${ }^{[64]}$ and propane to isopropanol[65] in the hands of Raja and Ratnasamy, using oxygen as the oxidant and copper hexadecachloro phthalocyanine as the single-site active centre. Because the zeolitic cage distorts the flat $\mathrm{CuCl}_{16} \mathrm{Pc}$ into a shallow bowl, the latter creates a hydrophobic environment ${ }^{[66]}$ around the central metal atom, thereby boosting catalytic activity.

Jacobs et al[69] encapsulated cis-[Mn(bpy) $\left.{ }_{2}\right]^{2+}$ complexes (bpy ( bipyridine) within the micropores of zeolite-Y and used the resulting catalyst for the epoxidation of alkenes with $\mathrm{H}_{2} \mathrm{O}_{2}$. This proceeded without complications of competing processes, such as the decomposition of the peroxide. High yields of the epoxides of hex-1-ene, cyclohexene, dodec-1-ene and cyclododecene were obtained. These catalysts are quite robust, and may be repeatedly re-used without reported loss of activity. Electronic factors are thought to play a key role ${ }^{[69]}$ in the performance of the encapsulated cis- $\left[\mathrm{Mn}(\mathrm{bpy})_{2}\right]^{2+}$, it being argued that the $\mathrm{H}_{2} \mathrm{O}_{2}$ activates the $\mathrm{Mn}$ ions so as to produce a $\mathrm{Mn}^{(\mathrm{IV})}(\mathrm{O}$ function; which releases its oxygen in the critical act of addition across the double bond to form the epoxide. Bein et al[70] also used a "ship-in-bottle" alkene epoxidation catalyst formed inside the cages of zeolite $\mathrm{Y}$ when extra-framework $\mathrm{Mn}^{\mathrm{II}}$ cations were complexed with a trimethyl-triazocyclononane ligand (tmtacn), the role of the methyl groups being chiefly to protect the amine against oxidation by $\mathrm{H}_{2} \mathrm{O}_{2}$. In situ ESR measurements show that the catalytically active site is a $\mathrm{Mn}^{\mathrm{III}}-\mathrm{Mn}^{\mathrm{IV}}$ dinuclear complex.

The great practical advantages of "ship-in-bottle" SSHC are well illustrated in the recent work of Bäckvall et al[67] on ruthenium catalyzed aerobic oxidation of alcohols (where encapsulated cobalt Salophen was the active, single-site catalyst: $\mathrm{H}_{2}$ Salophen is 2.2'-[benzene1,2-diil-bis(nitrilomethylidyne)]diphenol. Apart from highlighting the usual advantages of being able to remove and re-use the 'ship-in-bottle' catalyst by simple filtration, these workers showed that this SSH catalyst had a higher specific rate than the homogeneous analogue. Moreover the zeolite (bottle) serves as a water acceptor, so that there is no necessity to introduce a separate one, and the zeolite also exhibits shape-selectivity in the oxidation of secondary alcohols.

Although not strictly an example of 'ship-in-bottle' catalysis in the sense described above, the recent ingenious strategy adopted by Strukul et al, ${ }^{[70 \mathrm{~b}]}$ in which they 'microencapsulate' the 
enzyme chloroperoxidase within a microporous cage of silica gel, conforms to the principle of site isolation and single-site catalysis. Such catalysts are effective in the enantioselective oxidation of sulfides to sulfoxides with $\mathrm{H}_{2} \mathrm{O}_{2}$.

\section{Single-Site, Open-Structure Solid Catalysts}

Unlike bulk metal, alloy and other binary continuous solid catalysts, openstructure aluminosilicates (embracing natural and synthetic zeolites) as well as open-structure aluminophosphates (AIPOs), particularly frameworksubstituted variants (MAIPOs where $\mathrm{M}$ ? Mg, Co, Mn, Zn,...) are prime examples of uniform heterogeneous catalysts. Because the active sites in these catalysts are distributed in a spatially isolated and uniform manner ${ }^{[12]}$ they conform to Langmuir's classic assumption in that the energy released upon the uptake of adsorbate species is constant up to monolayer coverage. This energetic uniformity is seen vividly in the calorimetric work ${ }^{[71]}$ cited in Figure 20, where there is essentially a constant enthalpy of adsorption of pyridine on the Brönsted acid sites of the so-called pentasil zeolite H-ZSM-5 up until all the sites are neutralised (i.e. up to monolayer coverage of the catalytically active acid centres).

\section{(Figure 20 here)}

In zeolitic and MAlPO catalysts, the Brönsted active sites, which may be represented as ? $\mathrm{Si}\left(\mathrm{O}(\mathrm{H})\left(\mathrm{Al}\right.\right.$ ? and ? $\mathrm{M}^{\mathrm{I}}(\mathrm{O}(\mathrm{H})(\mathrm{P}$ ? respectively are so far apart spatially - and the higher the $\mathrm{Si} / \mathrm{Al}$ ratio in the acidic zeolite, $\mathrm{H}_{\mathrm{x}} \mathrm{Si}_{\mathrm{n}-\mathrm{x}} \mathrm{Al}_{\mathrm{x}} \mathrm{O}_{2 \mathrm{n}}$, or the higher the $\mathrm{P} / \mathrm{M}^{\mathrm{II}}$ ratio in the acidic MAlPO the further apart they are - that they are essentially isolated within the molecular sieve structure, thereby behaving as SSHC as defined in Section 1 above. An illustration of the nature of the "isolated" Brönsted acid sites is the efficient methanol dehydration catalyst (to produce light olefins) CoIIAIPO-18 is shown in Figure 21. [72] Also shown in this Figure is the isolated "redox" active site generated when the $\mathrm{Co}^{\mathrm{II}}$ has been converted to the higher oxidation state, $\mathrm{Co}^{\mathrm{III}}$. The respective $\mathrm{Co}(\mathrm{O}$ bond distances of the acid and redox active centres were determined under in situ conditions by X-ray absorption spectroscopy (XAFS). ${ }^{[28]}$

(Figure 21 here)

In the family of single-site acid catalysts MAlPO-18 (M ? Co $\left.{ }^{\mathrm{II}}, \mathrm{Mg}^{\mathrm{II}}, \mathrm{Zn}^{\mathrm{II}}, \mathrm{Mn}^{\mathrm{II}}, \ldots\right)$, which shape-selectively convert methanol to light olefins, ethene, propene and traces of butene, ${ }^{[73]}$ the active sites are the protons loosely attached to the oxygens adjacent to the doublycharged $\mathrm{M}^{\mathrm{II}}$ ions. These occupy a controllable small percentage (up to about 4 mole percent) of the sites normally occupied by framework $\mathrm{Al}{ }^{\mathrm{III}}$ ions. Likewise, when the transition-metal-ion is raised to a higher oxidation state $\left(\mathrm{CO}^{\mathrm{III}}\right)$, the 'redox' active centres, which are efficient ${ }^{[74,75]}$ in activating $\mathrm{C}(\mathrm{H}$ bonds in the presence of molecular oxygen, are again essentially isolated (as borne out by the XAFS data) and therefore are, by definition, a clear-cut example of SSHC (see Figure 22).

\section{(Figure 22 here)}

The widely used selective oxidation catalyst TS-1,[76] in which some of the silicon atoms that tenant the tetrahedral sites in the siliceous analogue of ZSM-5 are isomorphously replaced by $\mathrm{Ti}^{\mathrm{IV}}$ ions, is another archetypal example of a SSHC. So also is the (Fe)ZSM-5 catalyst that, in the hands of Panov et al, ${ }^{[77]}$ has been developed for the selective oxidation of aromatics such as benzene. (In Section 7, we discuss the mechanistic features of TS-1 in the light of the performance of a $\mathrm{Ti}^{\mathrm{IV}}$-centred catalyst belonging to category $\mathrm{D}$ ). 


\subsection{Bifunctional Single-Site Open-Structure Catalysts}

Whereas homogeneous catalysts are seldom bifunctional - a recent, unusual example involving allosteric regulation has, however, been reported ${ }^{[78]}$ - it is feasible to design single-site, open structure catalysts in which a Brönsted acidic site is wellseparated from a redox site in a shape-selective nanoporous matrix. The case in question involves ${ }^{[13]}$ another aluminophosphate matrix, known as MAlPO-36, which Raja et al, ${ }^{[79]}$ were able to modify so as to create both strong Brönsted acid sites (loosely attached protons) adjacent to $\mathrm{M}^{\mathrm{II}}$ ions such as $\mathrm{Mg}^{\mathrm{II}}$ or $\mathrm{Co}^{\mathrm{II}}$ as well as strong redox sites (where $\mathrm{Al}^{\mathrm{III}}$ is replaced by $\mathrm{Co}^{\mathrm{III}}$ ). Such a catalyst designated $\mathrm{M}^{\mathrm{II}} \mathrm{M}^{\mathrm{III}} \mathrm{AlPO}-36$ performs well in converting cyclohexanone to its oxime and then to (-caprolactam in the presence of $\mathrm{O}_{2}$ and ammonia.

(Scheme 4 here)

This sequence of consecutive conversions occurs freely because (see Figure 23): (a) hydroxylamine, $\mathrm{NH}_{2} \mathrm{OH}$, is readily formed in situ inside the pores from $\mathrm{NH}_{3}$ and $\mathrm{O}_{2}$ at the $\mathrm{M}^{\mathrm{III}}$ active sites; and (b) the $\mathrm{NH}_{2} \mathrm{OH}$ converts (1) to (2) both inside and outside the pores of the catalyst, and, likewise, at the Brönsted acid sites (2) is isomerised to (3) inside the pores of the molecular sieve catalyst.

(Figure 23 here)

Recent work ${ }^{[80]}$ in which a systematic variation was introduced first to the strength of the isolated Brönsted acid sites (by, for example, keeping a fixed redox site (CoIII) and vice versa (keeping a fixed acid site and changing the redox site) has led to a viable industrial method of producing (-caprolactam, which has been patented.

\subsection{Open-Structure Chiral SSH Catalysts}

It has not yet proved possible to prepare an open-structure, synthetic zeolite or open-structure MAIPO solid which possesses intrinsic chirality. It has, however, been possible, as first demonstrated by Hutchings et al, ${ }^{[58,81]}$ to modify the supercage of an acidic zeolite catalyst $(\mathrm{H}-\mathrm{Y})$ so as to create the chiral environment required to favour the formation of one of a pair of diastereoisomeric transition states, which is a necessary condition for enantioselective conversion. Full details have been given by Hutchings in an earlier review. ${ }^{[58]}$ In essence, by adding a chiral agent (either $\mathrm{R}$ or S) 1,3 dithiane1-oxide to a zeolite $\mathrm{H}$ $\mathrm{Y}$ that has been mildly de-aluminated, a well-defined single-site (Figure 24) active center is created which, kinetically enantioselectively resolves (in a gas-phase, acid catalyzed dehydration) racemic butan-2-ol. Hutchings et al, ${ }^{[82]}$ have also succeeded to effect enantioselective aziridination of alkenes (employing [N-(p-tolylsulfonyl)imino) phenyliodinane $\{\mathrm{PhI}=\mathrm{NTs}\}$ ) as the nitrogen source, with a single-site $\mathrm{Cu}^{\mathrm{II}}$-exchanged zeolite $\mathrm{HY}$ - see Figure 25.

(Figures 24 and 25 here)

\section{A Selection of Examples Illustrating Practical Applications of SSHC}

In addition to the examples that have been cited earlier in the description of various categories (summarized in Table 1) of SSHC, we illustrate below further instances encompassing both laboratory (research)-scale and industrially-used solid catalysts where the single-site, active centres are uniformly distributed, in a spatial sense, over the two-dimensional or threedimensional surfaces in question. Many of the examples highlighted are of particular value in the general quest for clean technology and green chemistry, 
with several instances in which the catalysts themselves are environmentally benign and the reactions that they facilitate (involving, for example, oxygen or air instead of nitric acid as an oxidant) even more so. Table 2 sets out the broad classification of the illustrative examples.

(Table 2 here)

We shall also illustrate how, (i) recent computational chemical procedures, combined with in situ experimental studies of single-site catalysts, enable us to establish the mechanism of the $\mathrm{Ti}^{\mathrm{IV}}$-centred catalytic epoxidation of alkenes and, (ii) using functionalised silsesquioxane fragments, direct measurements of catalytic performance may be made of the same active site in both homogeneous and heterogeneous situations.

\subsection{Enzyme Mimics}

The analogy between the mode of action of enzymes on the one hand, and molecular sieve (open-structure) as well as "ship-in-bottle" catalysts on the other hand has frequently been drawn. ${ }^{[83-87]}$ In each case, cavities in the catalysts impose shape-selectivity that governs the "choice" of reactant species which is to be transformed, and the molecular complementarity and associated factors of the microenvironment at the active site facilitates ensuing chemical conversion. In designing inorganic enzyme mimics, ${ }^{[88-90]}$ the key desiderata are high activity coupled with high selectivity and an ability to function at ambient temperatures and pressures. In general, inorganic enzyme mimics are thermally and mechanically stable, robust, and are usually readily capable of being regenerated when (through "poisoning" of active sites, for example) their performance diminishes. Moreover, because much is now known about ways of designing the molecular dimensions, ${ }^{[91,92]}$ degree of hydrophobicity ${ }^{[66]}$ and other features of open-structure inorganic catalysts, genuine inorganic mimics of certain enzymes may be prepared. In addition, a range of highly refined techniques has been evolved to probe, under operating conditions, ${ }^{[13,14,93,94]}$ the behaviour of reactant species and the active sites inside the cavities of open-structure inorganic solids.

\section{A Tyrosinase Mimic}

Copper-containing monooxygenase enzymes, like tyrosinase (EC 1.14.18.1) reversibly bind $\mathrm{O}_{2}$ and catalyze two different reactions - the hydroxylation of monophenols to ortho-diphenols (monophenolase activity) and the oxidation of the ortho-diphenols to ortho-quinones (diphenolase activity) using molecular oxygen as the oxidant. The active site contains a pair of antiferromagnetically-coupled copper ions. Even though several homogeneous models of tyrosinase have been proposed, none of them actually catalyzes the conversion of L-tyrosine to LDOPA (the reaction the enzyme catalyzes), nor has a heterogeneous solid mimic of tyrosinase been reported so far. Raja and Ratnasamy ${ }^{[95,96]}$ have shown that dimeric copper-acetate complexes, encapsulated within the microcavities of porous solids (zeolites X, Y and MCM-22), were effective in converting L-tyrosine to L-DOPA (as shown in Scheme 5). Their catalysts (enzyme mimics) also displayed high substrate specificity (only monophenols were oxidized) and regioselectivity (hydroxylation always occurred at the position ortho to the $-\mathrm{OH}$ group). A linear correlation was obtained between the concentration of the encapsulated copper acetate dimers (estimated from the integrated intensity of the seven-line ESR spectra) and monophenol conversion, suggesting that these copper atom dimers are the active sites in the activation of dioxygen. ${ }^{[95]}$ The turnover frequencies for the encapsulated catalysts are higher than their neat 
analogues, suggesting that these copper dimers are well-isolated in the molecular sieve matrix.

(Scheme 5 here)

\section{Methane Monooxygenase Mimic}

Methane monooxygenases are a group of enzymes (molecular mass ca $300 \mathrm{kD}$ ) extractable from methanotropic bacteria. These enzymes are able to hydroxylate methane to yield methanol, an extremely valuable commodity chemical (produced mainly on an industrial scale by steam-reforming of natural gas). Raja and Ratnasamy ${ }^{[64]}$ have shown that 'ship-in-bottle' SSHC, consisting of encapsulated complexes of $\mathrm{Fe}$ and $\mathrm{Cu}$ phthalocyanine (see Figure 19 above) in which all or most of the hydrogen atoms have been replaced by electron-withdrawing substituents (halogens or nitro groups) may convert methane in air at $273 \mathrm{~K}$ to methanol and formaldehyde as principal products (Scheme 6). The role of the solvent (acetonitrile) is quite important in this conversion, but detrimental to the commercial exploitation of this technology.

(Scheme 6 here)

\section{Haloperoxidase Mimic}

Haloperoxidases, which occur widely in marine organisms, are enzymes which catalyze the oxidation of a halide $\left(\mathrm{Cl}^{-}, \mathrm{Br}^{-}\right.$or $\left.\mathrm{I}^{-}\right)$, by hydrogen peroxide, in such as manner as to achieve concomitant halogenation of certain organic substrates. However, in the absence of organic substrates, it has been shown ${ }^{[97]}$ that these enzymes convert the halide ions to the molecular halogen (see Scheme 7).

\section{(Scheme 7 here)}

$\mathrm{CuCl}_{16} \mathrm{Pc}$ complexes, encapsulated within the supercages of zeolites $\mathrm{X}$ and $\mathrm{Y}$, are effective for the oxychlorination and oxybromination of a wide range of aromatic compounds, at ambient conditions, using molecular oxygen as the oxidant, in the presence of a suitable alkali halide (such as $\mathrm{KBr}$ ) - see Table 3. The encapsulation of the $\mathrm{CuCl}_{16} \mathrm{Pc}$ complex results in ortho-para orientation among the nuclear halogenated products with virtually no attack at the meta-position. Further, the in situ formation of $\mathrm{Br}_{2}$ from $\mathrm{KBr}$ (established by spectroscopic methods), and, the $\mathrm{pH}$ dependence of the catalytic activity, suggests that the halogenating agent is an electrophilic species. ${ }^{[97,98]}$

(Table 3 here)

\section{Hydroxylases}

By virtue of their ability selectively to bind a linear alkane and to so orient it with respect to the active oxidant at the active site, the so-called (-hydroxylases can achieve the remarkable regioselective hydroxylation of terminal methyl groups. Herron and Tolman ${ }^{[99]}$ made significant progress in designing a completely inorganic mimic of the alkane (hydroxylases by using encapsulated $\mathrm{Pd}(0)$ and $\mathrm{Fe}(\mathrm{II})$ entities inside zeolite A. This 'ship-inbottle' design succeeds in producing hydrogen peroxide from a $\mathrm{O}_{2} / \mathrm{H}_{2}$ mixture, but they were unable selectively to functionalise only the terminal methyl group of n-octane with this catalyst. Open-structure SSH catalysts (such as M ${ }^{\mathrm{III}} \mathrm{AlPO}-18$ where M ( Co or Mn) are, however, very effective ${ }^{[74,75,100]}$ in preferentially hydroxylating the terminal methyl groups of linear alkanes $\left(\mathrm{C}_{\mathrm{n}} \mathrm{H}_{2 \mathrm{n}+2}, \mathrm{n}=6-12\right)$ in air or oxygen (see Figure $22 \mathrm{~b}$ ). Indeed it is also possible with this category of SSH catalysts, provided the degree of substitution of framework $\mathrm{Al}^{\mathrm{III}}$ ions by $\mathrm{M}^{\mathrm{III}}$ ions (Co or 
$\mathrm{Mn}$ ), is large enough ( $\mathrm{ca} 10$ atom percent), to convert n-hexane to adipic acid in air under mild conditions. ${ }^{[101]}$

(Scheme 8 here)

\subsection{SSHCs for Sustainable Development and Clean Technology}

Selective hydrogenation as well as selective oxidation catalysis nowadays loom progressively larger in the general area of clean (green) chemistry and sustainable development. ${ }^{[102,103]}$

\section{Solvent-Free Selective Hydrogenations as Candidates for the Production of Commodity Chemicals}

The drive to minimize the use of volatile solvents or replace them with environmentally more benign ones (such as supercritical $\mathrm{CO}_{2}$ ) has, as its logical conclusion, the development of catalysts that may effect conversions in a solvent-free manner. ${ }^{[45,49]}$ Table 4 enumerates many of the selective hydrogenation processes, leading to much-used commodity chemicals, that are catalyzed by single-site, multinuclear bimetallic nanoparticles. (Note that the turnover frequencies (TOFs) are exceptionally high under relatively mild conditions of temperature and pressure). The selective hydrogenation of benzene to cyclohexene is particularly noteworthy as it opens up a new, environmentally benign route to adipic acid that disperses with the need to use conc. nitric acid as an oxidant (with consequential production of massive quantities the greenhouse gas, $\mathrm{N}_{2} \mathrm{O}$ ). Cyclohexene, with the "right" catalyst is converted to adipic acid using $\mathrm{H}_{2} \mathrm{O}_{2}$ as oxidant.[104,105]

(Table 4 here)

\section{Adipic Acid from Sustainable Sources using a Single-Site Supported $\mathbf{R u}_{10} \mathbf{P t}_{2}$ Nanoparticle Catalyst}

With the aid of biocatalysts, muconic acid may be readily produced ${ }^{[106 a]}$ from corn, a renewable feedstock. We have discovered[106b] that a single-site $\mathrm{Ru}_{10} \mathrm{Pt}_{2}$ multinuclear nanoparticle catalyst supported on mesoporous silica is superior to a variety comparable catalysts (e.g. $\mathrm{Rh} / \mathrm{Al}_{2} \mathrm{O}_{3}, \mathrm{Pt} / \mathrm{SiO}_{2}, \mathrm{Pd}_{6} \mathrm{Ru}_{6} / \mathrm{SiO}_{2}$ ) in converting muconic acid, in a single-step to adipic acid (see Scheme 9).

(Scheme 9 here)

\section{Commercially and Environmentally Important Selective Oxidation Processes that may be Effected by SSHCs}

A selection of the important selective oxidations that may be effected by an range of isolated (single-site) transition-metal ions grafted into mesoporous silica is shown in Figure 26. This summarizes ${ }^{[31]}$ our own work and that of others, notably Tilley, ${ }^{[33]}$ Bell[35] and Wachs. ${ }^{[107]}$ All the reactions catalyzed by Fe were studied by Bell and Tilley. ${ }^{[33-35]}$ The reagents used for the selective oxidations vary according to the reaction and the catalyst in question. Sometimes $\mathrm{H}_{2} \mathrm{O}_{2}$ is the oxidant, ${ }^{[108]}$ sometimes alkyl hydroperoxides ${ }^{[109]}$ (such as tert. butyl hydroperoxide, TBHP) and occasionally oxygen itself (as in the case of the oxidative dehydrogenation of methanol to formaldehyde).

(Figure 26 here)

Epoxidation of alkenes with $\mathrm{Ti} / \mathrm{SiO}_{2}$ catalysts is of major industrial importance in the 
production of fine chemical and several other commodities.[110] For example, the catalytic conversion of propylene to propylene oxide over $\mathrm{Ti} / \mathrm{SiO}_{2}$ in the presence of alkyl hydroperoxides is an industrially important epoxidation process that accounts for an annual production of more than one million tons of propylene oxide world wide. As a result of recent Italian research work, ${ }^{[111,112]}$ there are now real prospects that (renewable) vegetable oils and fats, which are good sources for two popular unsaturated fatty methyl esters - methyl-(Z)-9-octadecanoate (methyl oleate, structure 1 in Figure 27) and methyl-(E)-9-octadecanoate, methyl elaidate, structure 2 may be benignly epoxidized with a $\mathrm{Ti}^{\mathrm{IV}}$-centred silica (single-site) catalyst (see Figure 27) with TBHP.

\section{(Figure 27 here)}

In the past, an environmentally unfriendly "peracid" method was used to epoxidize the naturally occurring compounds. Ravasio et al ${ }^{[12]}$ have also shown that the $\mathrm{Ti}^{\mathrm{IV}}$-centred single-site catalyst also effectively converts the doubly unsaturated components of soya bean oil into useful epoxides - another important step towards sustainable development.

Ravasio et al ${ }^{[112]}$ have also shown that the $\mathrm{Ti}^{\mathrm{IV}}$-ion SSHC (on silica) is particularly good in epoxidizing terpenes such as (-terpinol, carveol and limonene under mild conditions (see Table 5).

(Table 5 here)

\section{Other Economically Important Examples of $\mathbf{T i}^{\mathrm{IV}}$-Catalyzed (Single-Site) Selective Oxidations}

The open-structure microporous silica known as MFI (the accepted international notation for the framework ZSM-5), ${ }^{[113]}$ when it contains isolated $\mathrm{Ti}^{\mathrm{IV}}$ ions replacing some of the $\mathrm{Si}^{\mathrm{IV}}$ tetrahedral sites is known as $\mathrm{TS}-1$, and is an exceptionally good single-site heterogeneous selective oxidation catalyst. ${ }^{[114]}$ Some key processes using $\mathrm{H}_{2} \mathrm{O}_{2}$ as oxidant are indicated in Scheme 10 .

(Scheme 10 here)

\section{Mechanism and Energetics of Epoxidation and Comparison between the Heterogeneous and Homogeneous Processes.}

Figure 28 shows the kinship that exists between the 4-coordinated $\mathrm{Ti}^{\mathrm{IV}}$ active site for both the microporous and mesoporous silica frameworks that house the isolated $\mathrm{Ti}^{\mathrm{IV}}$ sites. ${ }^{[115]}$ Using a joint experimental (X-ray absorption) and computational study, in the course of which we could directly probe the environment of the $\mathrm{Ti}^{\mathrm{IV}}$-centred active site under steady-state during the actual epoxidation, we could arrive at the pathway and associated energetics for the mechanism of the epoxidation. These are shown in Figure 29.

(Figures 28 and 29 here)

Coordination of the oxygen atoms of the peroxide to the $\mathrm{Ti}^{\mathrm{IV}}$-active centre activates them by increasing their electrophilicity; and the computations reveal that the oxygens may be readily abstracted by the nucleophilic alkenes to form the epoxides. As shown in the figure, subsequent loss of the water regenerates the original tripodal (4-coordinated) $\mathrm{Ti}^{\mathrm{IV}}$ active center. In line with this mechanism, which harmonizes with the independent work of Roesky et al[116] (on the formation of titanium alkylhydroperoxide), it is not surprising that when one of the three silicons, to which, via oxygen, the $\mathrm{Ti}^{\mathrm{IV}}$ site is tripodally attached, is replaced by germanium, there is an increase in the rate of epoxidation.[117]

Experiments with soluble, molecular (homogeneous) analogues of the heterogeneous 
$\mathrm{Ti} / \mathrm{SiO}_{2}$ epoxidation catalyst using the silsesquioxanes: $\left[\left(\mathrm{c}-\mathrm{C}_{5} \mathrm{H}_{9}\right)_{7} \mathrm{Si}_{7} \mathrm{O}_{12} \mathrm{TiOXPh}_{3}\right]$, where $\mathrm{X}=\mathrm{Si}$, Ge and $\mathrm{Sn}$ - in which XAFS and kinetic measurements could be carried out in solution - not only confirm that replacement of Si by Ge (or Sn) at the active site enhances the rate of epoxidation, they also show that the turnover frequencies for the 'hetero' and 'homo' active sites are numerically similar. ${ }^{[117]}$

\subsection{In Situ Generation of Hazardous Reagents Using Open-Structure SSHC}

The in situ production and containment of aggressive and hazardous reagents (as well as the avoidance of the use of ecologically harmful ones) has been much assisted by the design of appropriate open-structure SSHC, such as those consisting of metal-ion-framework-substituted aluminophosphates, MAlPOs. A range of such nanoporous catalysts designed by us has been described previously.[13,100,118] We give two specific examples here: (i) a Baeyer-Villiger process (for the conversion of cyclic ketones to lactones, and (ii) the generation of hydroxylamine in the intrapore cavities and channels of bifunctional SSHC.

\section{(Scheme 11 here)}

In the former, aggressive permonosulphuric acid (used by Baeyer and Villiger) or methyl rhenium trioxide or any added peroxide are avoided and $\mathrm{O}_{2}$ is used in the presence of (a sacrificial) benzaldehyde. ${ }^{[119]}$ In the latter, ammonia and oxygen generate hydroxylamine at the redox active sites of the bifunctional catalyst.

\section{(Scheme 12 here)}

The convenience of having a bifunctional open-structure SSHC, such as that shown in Figure 24 above, commends itself commercially, since this is an extremely direct way of generating cyclohexanone oxime, and its isomerized product, (-caprolactam, which, on polymerization, yields nylon. ${ }^{[120]}$

Another example where SSHC has proved valuable is that of the enzyme mimic for haloperoxidase, described in Section 7.1.3 above. With such a catalyst, one dispenses with the need to add neat halogen to the sphere of reaction.

\subsection{Chiral Conversions with SSHC}

There is an ever-growing need for high-performance, heterogeneous, recyclable asymmetric catalysts, because, inter alia, as with other areas of catalytic conversion $^{121}$ they should surpass their homogeneous analogues so far as the important practical consideration of separation of products is concerned. Of late, many new strategies have been proposed to accelerate the arrival of reliable, robust heterogeneous asymmetric catalysts, and a recent monograph ${ }^{[56]}$ along with other publications ${ }^{[62,122]}$ outline various possible strategies for "imprinting" a surface with chirality.

We have already alluded to the ingenious method of Hutchings et al, ${ }^{[58]}$ who, in turn, refer to the elegant work of Bianchini ${ }^{[42,124]}$ and others especially that of Corma and Garcia ${ }^{[125]}$ and Xiang et $a{ }^{[126]}$ (who successfully immobilized the Sharpless titanium-diethyltartrate system). Here, for illustrative purposes, we focus first on Jacobs's work on the coordination of CrIII (Salen) on functionalized silica for the asymmetric ring opening (ARO) of epoxides ${ }^{[127 a]}$ and later that of Maschmeyer and Sheldon ${ }^{[127 b]}$ on the use of single-site, immobilized Rh-MonoPhos, a chiral monodentate ligand. We also summarize the practical advantages of our own approach ${ }^{[43-45,57]}$ to designing constrained (single-site) chiral catalysts.

The heterogeneous ARO of meso-epoxides with trimethylsilylazide $\left(\mathrm{TMSN}_{3}\right)$ catalysed by 
a CrIII (Salen) moiety coordinated to an aminopropyl functionalized (high-area) silica combines good enantioselectivity with high conversions and a pronounced lack of tendency for the catalyst to be leached off its support. Thus, in the ring-opening of cyclohexene oxide, under the conditions given in Scheme 13, conversions are always in excess of 99 percent and ee values range (in ten successive runs to test leachability) from a low of 65 to a high of 77 percent.

\section{(Scheme 13 here)}

Feringa and his colleagues demonstrated ${ }^{[127 c]}$ that rhodium complexes with chiral monodentate ligands such as phosphoramidites (MonoPhos) are very powerful tools for reduction, and that homogeneous catalysts based on these ligands are highly enantioselective. Using the specially prepared mesoporous silica known as TUD-1,[127b] into the framework of which isolated $\mathrm{Al}^{\mathrm{III}}$ ions have replaced some $\mathrm{Si}^{\mathrm{IV}}$ ions (thereby producing a high-area solid designated AlTUD1), Maschmeyer, Simons ${ }^{[127 b]}$ et al showed that ionically-bound Rh-phosphoramidite exhibited excellent enantioselectivity in the asymmetric hydrogenation of methyl-2-acetamidoacrylate. The ionic binding procedure of Rege et al, ${ }^{[46]}$ also used by us, ${ }^{[44]}$ is a rapid, convenient method of generating highly efficient, robust, and recyclable SSH catalysts for enantioselective hydrogenations that may be carried out using water as solvent.

\section{(Scheme 14 here)}

So far as the use of our own approach to constrained chiral catalysis is concerned, we emphasize that highly efficient enantioselective hydrogenations, of prochiral molecules that yield products of considerable commercial significance, have been achieved. Thus:

* two distinct metal centres $\{\mathrm{Rh}(\mathrm{I})$ and $\mathrm{Pd}(\mathrm{II})$,

* three distinct diamino ligands (see Table 6)

* two methods of producing the single-site immobilized organometallic (covalent and ionic) and

* two specific examples of hydrogenations, have been demonstrated.

(Table 6 here)

The relevant catalytic activities, selectivities and enantiomeric excesses (ee) for the various homogeneous and heterogeneous $\mathrm{Rh}(\mathrm{I})$ catalysts are summarized for the asymmetric hydrogenation of methyl benzoyl formate in Table 6; and the corresponding catalytic performance for the $\mathrm{Pd}(\mathrm{II})$-centred asymmetric catalysts for the hydrogenation of both E-(()-phenylcinnamic acid (PCA) and methyl benzoyl formate (MBF) are shown in Table 7. Several patents, ${ }^{[128-}$ 130] based on these constrained, single-site, asymmetric heterogeneous catalysts, have been recently filed by German industry (on behalf of the Cambridge Inventors).

(Table 7 here)

\subsection{Some Miscellaneous Examples}

Already in this review we have cited a number of important examples where single-site, open-structure heterogeneous catalysts hold sway. The majority of zeolites (as well as the growing number of metal-substituted aluminophosphates) used in industry possess isolated, single-site active centers. They catalyze a large number of commercially important reactions and also offer ideal testing grounds for fundamental studies. Both these facets are dealt with in Section 7.5.1. In the remainder (Sections 7.5.2, 7.5.3 and 7.5.4) potential large-scale operations involving hydroformylation, metathesis and polymerization are outlined. 


\subsubsection{Solid Acid Catalysts}

In all so-called pentasil[83] zeolites (e.g. ZSM-5 and ZSM-11) where the Si/Al ratios are seldom less than 10 and often much in excess of this value, and in numerous other aluminosilicate and aluminophosphate open-structure solids (such as faujasite (zeolite Y), ferrierite, erionite, and SAPO-34), a huge variety of (Brönsted) acid-catalyzed reactions may be carried out. Short ${ }^{[131,132]}$ and extended reviews ${ }^{[133-135]}$ of this vital class of reactions, that embrace both the petrochemical and fine-chemical world, are already available. Table 7 gives an enumeration of some of these reactions.

(Table 8 here)

\subsubsection{Shape-Selective, Solid-Acid, Single-Site Zeolitic Catalysts and their Kinship with Enzymes}

As mentioned in Section 7.1, the analogy between the mode of action of an enzyme on the one hand and a "ship-in-bottle" SSHC catalyst can be quite striking. It is also true that certain acid-catalyzed reactions in zeolitic solids also have a kinship with enzyme action. Thus, the Brönsted-acid catalyzed cyclo-dimerization of 3-hydroxy-3-methylbutan-2-one (HMB) ${ }^{[89]}$ over a $\mathrm{H}^{+}$form of (synthetic) ferrierite ( $\mathrm{Si} / \mathrm{Al}$ ratio of 40 ) yields only one product, whereas $\mathrm{HMB}$ in acidic solution generates a wide variety of products - see Scheme 15

\section{(Scheme 15 here)}

Likewise, acetaldehyde[${ }^{[90]}$ is catalytically transformed in acidic solution to a broad distribution of products, whereas within the space-restricting cages of $\mathrm{H}^{+}$ferrierite cyclotrimerization occurs with 100 percent selectivity at ambient temperature.

7.5.2. Hydroformylations, Metathesis and Polymerizations using SSHC Assembled from Anchored Organometallic Species ${ }^{[134,136-138]}$

Bianchini et al ${ }^{[42]}$ have shown how to overcome the disadvantages that homogeneous $\mathrm{Rh}(\mathrm{I})$ complexes possess by anchoring them, in a single-site fashion, on to a silica surface (see Figure 11 above). Although hydroformylation (metal-complex) catalysts have been successfully immobilized at silica surfaces their activities and selectivities have not yet reached values high enough to rival those registered by their homogeneous counterparts, which they surpass in ease of separation of products from reactants. The dinuclear rhodium (II) catalyst studied by Maschmeyer et al ${ }^{[139]}$ is a case in point. Here, it was possible to pin down the precise structure of the active catalyst from a crystallographic study of the soluble silsesquioxane derivative (see Figure 30)

\section{(Figure 30 here)}

Coperét and coworkers, ${ }^{[22]}$ using non-porous silica supports were able to immobilize organometallic metathesis catalysts, in which the central atom was either Ta, Mo, W or Re: examples of such well-defined silica-supported metallocarbenes and carbynes were shown in Figure 10 above. It is noteworthy[140-141] that, in contrast to the di-rhodium catalyst for hydroformylation, the activities, selectivities and lifetimes of these SSHC are close to - and in some instances superior - to those of the corresponding homogeneous catalysts.

The so-called constrained geometry-inspired catalysts (CGCs) of Mc Kittrick and Jones, ${ }^{[41,142]}$ mentioned earlier - see Section 3.3 and Schemes 1 and 2 - in which a Ti-centred catalyst is immobilized, site-isolated fashion, at a silica surface exhibit exceptionally good 
catalytic performance in the room-temperature polymerization of ethene (in the presence of an alkyl- aluminium and pentafluorophenyl activator). And a text book example of polymerization at a SSHC of the Brönsted acid type is contained in the work of Zecchina et al. ${ }^{[143]}$ These workers showed (using in situ FTIR) that acetylene, methylacetylene and ethylacetylene interact with the Brönsted acid sites of H(ZSM-5 with the formation of hydrogen-bonded (precursor) species characterized by well-defined IR properties (see Scheme 16). These species are then protonated (by the catalyst) to give intensely coloured carbocationic species. Insertion of the monomer into the first protonation product lead first to oligomeric species with the carbocationic character and then to the polymer (like polyacetylene). ${ }^{[144]}$

\section{(Scheme 16 here)}

Other examples of heterogeneous, single-site catalysts have been reported in the literature, but almost invariably none of these has an open-structure of the kind highlighted here (where we have three-dimensional surfaces over which the active sites are distributed). A good example is contained in the work of Kaneda et al, ${ }^{[145]}$ who created monomeric species of Ru-centered sites at the surface of hydroxyapatite. Such sites are effective in the catalytic aerobic oxidation of alcohols. But, as yet, no one has prepared mesoporous hydroxyapatites possessing an architecture reminiscent of the mesoporous silicas described herein.

\section{Envoi}

The numerous practical and pedagogic advantages of identifying the concept, and aspiring towards the preparation, of single-site heterogeneous catalysts are summarized in Table 9.

\section{(Table 9 here)}

A multiplicity of examples, cited above and in earlier articles (see refs. 13, 31 and 45), encompassing a variety of selective oxidations (including the oxyfunctionalization of alkanes and the benign epoxidation of replenishable terpenes and the esters of naturally occurring unsaturated fatty acids), selective hydrogenation of polyenes and unsaturated (prochiral) ketoesters, dehydrations of alkanols, alkylations, allylic aminations, ammoximations, oxyhalogenations, isomerizations, oligomerizations and polymerization of alkenes and aldehydes, demonstrate the veracity of the contents of Table 9. A large fraction of these catalyzed conversions is achieved using open-structure solids, especially metal-substituted mesoporous (15 to $250 \AA$ dia.) silica and microporous ( 3.8 to $7.5 \AA$ dia.) aluminophosphates, into which, as isolated entities more than a quarter of the elements of the Periodic Table may be incorporated either as well-separated redox or acid-base (or both) active centers. The resulting high-area open-structure and molecularly accessible solids possess, in effect, three-dimensional surfaces over which the active sites are judiciously placed.

\section{Acknowledgements}

We are grateful to our colleague Prod. B. F. G. Johnson for his stimulating contributions to our endeavors, to other colleagues mentioned in the text, and to a variety of research sponsors including EPSRC, Bayer Chemicals and BP. JMT wishes to thank Prof. Viveka Alfredsson and her colleagues at Physical Chemistry I, University of Lund, for their hospitality. 


\section{References}

[1] J. D. Horvath, A. J. Gellman, Top. Catal. 2003, 25, 9.

[2] Y. Y. Yeo, L. Vattuone, D. A. King, J. Chem. Phys. 1997, 106, 392.

[3] H. S. Taylor, Proc. Roy. Soc. A, 1925, 108, 105

[4] J. M. Thomas, Adv. Catalysis, 1969, 19, 293

[5] (a) G. A. Samorjai, Introduction to Surface Chemistry and Catalysis, Wiley, New York, 1994; (b) S. Dahl, A. Logadottir, R. C. Egeberg, J. H. Larsen, I. Chorkendorff, E. Tornqvist, J. K. Norskov, Phys. Rev. Lett. 1999, 83, 1814

[6] E. J. Arlman, P. Cossee, J. Catal. 1964, 3, 99.

[7] R. Imbihl, G. Ertl, Chem. Rev. 1995, 95, 697.

[8] G. Ertl, H. J. Freund, Phys. Today 1999, 52, 32.

[9] V. P. Zhdanov, B. Kasemo, Phys. Chem. Chem. Phys. 2004, 6, 4347

[10] H. Schubert, U. Tegtmeyer, D. Herein, X. Bao, M. Muhler, R. Schlogl, Catal. Lett. 1995, 33, 305.

[11] (a) C. T. Campbell, Science 2004, 306, 234; (b) M. S. Chen, D. W. Goodman, Science 2004, 306, 252.

[12] J. M. Thomas, Angew. Chem. Int. Ed. Engl. 1988, 27, 1673.

[13] J. M. Thomas, Angew. Chem. Int. Ed. 1999, 38, 3589.

[14] B. M. Weckhuysen in In Situ Spectroscopy of Catalysts (ed. B. M. Weckhuysen) American Scientific Publishers, New York, 2004, p1

[15] (a) F. J. Feher, D. A. Newman, J. F. Walzer, J. Am. Chem. Soc. 1989, 111, 1741; (b) H. C. L. Abbenhuis, S. Krijnen, R. A. van Santen, Chem. Commun. 1997, 331.

[16] R. Murugavel, A. Voigt, M. G. Walawalkar, H. W. Roesky, Chem. Rev. 1996, 96, 2205.

[17] J. M. Thomas, G. Sankar, M. C. Klunduk, M. P. Attfield, T. Maschmeyer, B. F. G. Johnson, R. G. Bell, J. Phys. Chem. B 1999, 103, 8809

[18] see J. M. Basset, A. Choplin, J. Mol. Cat. 1983, 21, 95

[19] (a) D. G. H. Ballard, Adv. Catalysis, 1973, 23, 263; (b) J. P. Candlin, H. Thomas, Adv. Chem. Ser. 1974, 132, 212

[20] C. Coperet, M. Chabanas, R. P. Saint-Arroman, J. M. Basset, Angew. Chem. Int. Ed. 2003, 42, 156

[21] C. T. Kresge, M. E. Leonowicz, W. J. Roth, J. C. Vartuli, J. S. Beck, Nature 1992, 359, 710.

[22] S. Inagaki, Y. Fukushima, K. Kuroda, J. Chem. Soc. Chem. Commun. 1993, 680

[23] A. Corma, M. T. Navarro, J. P. Pariente, J. Chem. Soc. Chem. Commun. 1994, 147.

[24] G. Sankar, F. Rey, J. M. Thomas, G. N. Greaves, A. Corma, B. R. Dobson, A. J. Dent, J. Chem. Soc. Chem. Commun. 1994, 2279.

[25] J. M. Thomas, Nature 1994, 368, 289.

[26] P. T. Tanev, M. Chibwe, T. J. Pinnavaia, Nature 1994, 368, 321.

[27] (a) T. Maschmeyer, F. Rey, G. Sankar, J. M. Thomas, Nature 1995, 378, 159; (b) P. E. Sinclair, G. Sankar, C. R. A. Catlow, J. M. Thomas, T. Maschmeyer, J. Phys. Chem. B 1997, 101, 4232

[28] J. W. Couves, J. M. Thomas, D. Waller, R. H. Jones, A. J. Dent, G. E. Derbyshire, G. N. Greaves, Nature 1991, 354, 465.

[29] R. A. Sheldon, J. Mol. Catal. 1983, 20, 1.

[30] I. J. Shannon, T. Maschmeyer, R. D. Oldroyd, G. Sankar, J. M. Thomas, H. Pernot, J. P. Balikdjian, M. Che, J. Chem. Soc. Faraday Trans. 1998, 94, 1495.

[31] (a) J. M. Thomas, R. Raja, Stud. Surf. Sci. Catal. 2004, 148, 163; (b) A. Sakthivel, J. Zhao, F.E. Kühn, Catal. Lett. 2005, in press.

[32] J. Jarupatrakorn, J. D. Tilley, J. Am. Chem. Soc. 2002, 124, 8380. 
[33] K. L. Fujdala, T. D. Tilley, J. Catal. 2003, 216, 265.

[34] (a) C. Pak, A. T. Bell, T. D. Tilley, J. Catal. 2002, 206, 49; (b) I. J. Drake, K. L. Fujdala, A. T. Bell, T. D. Tilley, ibid. 2005, 230, 14.

[35] A. T. Bell, Science 2003, 299, 1688.

[36] S. Abbet, A. Sanchez, U. Heiz, W. D. Schneider, A. M. Ferrari, G. Pacchioni, N. Rosch, J. Am. Chem. Soc. 2000, 122, 3453.

[37] S. Abbet, U. Heiz, H. Hakkinen, U. Landman, Phys. Rev. Lett. 2001, 86, 5950.

[38] H. Ahn, C. P. Nicholas, T. J. Marks, Organometallics 2002, 21, 1788.

[39] H. Ahn, T. J. Marks, J. Am. Chem. Soc. 2002, 124, 7103.

[40] C. P. Nicholas, H. S. Ahn, T. J. Marks, J. Am. Chem. Soc. 2003, 125, 4325.

[41] M. W. McKittrick, C. W. Jones, J. Am. Chem. Soc. 2004, 126, 3052.

[42] C. Bianchini, D. G. Burnaby, J. Evans, P. Frediani, A. Meli, W. Oberhauser, R. Psaro, L. Sordelli, F. Vizza, J. Am. Chem. Soc. 1999, 121, 5961.

[43] J. Rouzaud, M. D. Jones, R. Raja, B. F. G. Johnson, J. M. Thomas, M. J. Duer, Helv. Chim. Acta 2003, 86, 1753.

[44] R. Raja, J. M. Thomas, M. D. Jones, B. F. G. Johnson, D. E. W. Vaughan, J. Am. Chem. Soc. 2003, $125,14982$.

[45] J. M. Thomas, R. Raja, J. Organomet. Chem. 2004, 689, 4110.

[46] F. M. de Rege, D. K. Morita, K. C. Ott, W. Tumas, R. D. Broene, Chem. Commun. 2000, 1797.

[47] W. Z. Zhou, J. M. Thomas, D. S. Shephard, B. F. G. Johnson, D. Ozkaya, T. Maschmeyer, R. G. Bell, Q. F. Ge, Science 1998, 280, 705.

[48] R. Raja, G. Sankar, S. Hermans, D. S. Shephard, S. Bromley, J. M. Thomas, B. F. G. Johnson, Chem. Commun. 1999, 1571.

[49] (a) J. M. Thomas, B. F. G. Johnson, R. Raja, G. Sankar, P. A. Midgley, Accounts Chem. Res. 2003, 36, 20; (b) If too high a surface density of tethered active sites is introduced within a mesopore, the active sites themselves become so close to one another that they are no longer isolated. Under these circumstances it is no longer valid to describe such prepared catalysts as "single-site." When, however, the length of the tether is sufficiently long that the pendant active-site now becomes close to the (opposite) wall of the pore, a new phenomenon occurs as described in the ensuing text.

[50] J. M. Thomas, R. Raja, G. Sankar, B. F. G. Johnson, D. W. Lewis, Chem. Eur. J. 2001, 7, 2973.

[51] J. M. Thomas, P. A. Midgley, Chem. Commun. 2004, 1253.

[52] J. M. Thomas, P. A. Midgley, T. J. V. Yates, J. S. Barnard, R. Raja, I. Arslan, M. Weyland, Angew. Chem. Int. Ed. 2004, 43, 6745.

[53] R. D. Adams, B. Captain, L. Zhu, J. Am. Chem. Soc. 2004, 126, 3042.

[54] R. D. Adams, B. Captain, J. Organomet. Chem. 2004, 689, 4521.

[55] H. Brunner in Applied Homogeneous Catalysis with Organometallic Compounds, (ed. B Cornils, W. A. Hermann) Vol. 1. Wiley-VCH, Weinheim, Germany, 1996, p206

[56] G. J. Hutchings, J. M. Thomas, D. J. Willock, Top. Catal. 2003, 25, 1.

[57] M. D. Jones, R. Raja, J. M. Thomas, B. F. G. Johnson, D. W. Lewis, J. Rouzaud, K. D. M. Harris, Angew. Chem Int. Ed. 2003, 42, 4326.

[58] G. J. Hutchings, Chem. Commun. 1999, 301.

[59] B. M. L. Dioos, W. A. Geurts, P. A. Jacobs, Catal. Lett. 2004, 97, 125.

[60] B. F. G. Johnson, S. A. Raynor, D. S. Shephard, T. Mashmeyer, J. M. Thomas, G. Sankar, S. Bromley, R. Oldroyd, L. Gladden, M. D. Mantle, Chem. Commun. 1999, 1167.

[61] S. A. Raynor, J. M. Thomas, R. Raja, B. F. G. Johnson, R. G. Bell, M. D. Mantle, Chem. Commun. 
2000, 1925.

[62] R. A Sheldon, H. van Bekkum (eds), Fine Chemicals Through Heterogeneous Catalysis, WileyVCH, Weinheim, 2001.

[63] N. Herron, Inorg. Chem. 1986, 25, 4714.

[64] R. Raja, P. Ratnasamy, Appl. Catal. A Gen. 1997, 158, L7.

[65] R. Raja, C. R. Jacob, P. Ratnasamy, Catal. Today 1999, 49, 171.

[66] S. Ray, S. Vasudevan, Inorg. Chem. 2003, 42, 1711.

[67] A. Zsigmond, F. Notheisz, G. Csjernyik, J. E. Backvall, Top. Catal. 2002, 19, 119.

[68] R. F. Parton, R. A. Uytterhoeven, P. A. Jacobs in Heterogeneous Catalysis and Fine Chemicals, ed. M. Guisnet, Elsevier, Amsterdam, 1995, p395

[69] P. P. Knops-Gerrits, D. Devos, F. Thibault-Starzyk, P. A. Jacobs, Nature 1994, 369, 543.

[70] (a) D. E. deVos, J. L. Meinershagen, T. Bein, Angew. Chem. Int. Ed. Engl. 1996, 35, 2211; (b) V. Trevisan, M. Signoretto, S. Colonna, V. Pironti, G. Strukul, Angew. Chem. Int. Ed. 2004, 43, 4097.

[71] D. J. Parrillo, C. Lee, R. J. Gorte, Appl. Catal. A Gen. 1994, 110, 67.

[72] J. M. Thomas, G. N. Greaves, G. Sankar, P. A. Wright, J. S. Chen, A. J. Dent, L. Marchese, Angew. Chem. Int. Ed. Engl. 1994, 33, 1871

[73] (a) P. A. Barrett, R. H. Jones, J. M. Thomas, G. Sankar, I. J. Shannon, C. R. A. Catlow, Chem. Commun. 1996, 2001; (b) J. S. Chen, J. M. Thomas, J. Chem. Soc. Chem. Commun. 1994, 603.

[74] R. Raja, J. M. Thomas, Chem. Commun. 1998, 1841.

[75] J. M. Thomas, R. Raja, G. Sankar, R. G. Bell, Nature, 1999, 398, 227

[76] B. Notari, Advances in Catalysis, 1996, 41, 253.

[77] G. Panov, Appl. Catal. A Gen. 1995, 123, N14.

[78] N. C. Gianneschi, P. A. Bertin, S. T. Nguyen, C. A. Mirkin, L. N. Zakharov, A. L. Rheingold, J. Am. Chem. Soc. 2003, 125, 10508.

[79] R. Raja, G. Sankar, J. M. Thomas, J. Am. Chem. Soc. 2001, 123, 8153.

[80] W. Buijs, R. Raja, J. M. Thomas, H. Wolters, Catal. Lett. 2003, 91, 253.

[81] S. Feast, M. Rafiq, H. Siddiqui, R. P. K. Wells, D. J. Willock, F. King, C. H. Rochester, D. Bethell, P. C. B. Page, G. J. Hutchings, J. Catal. 1997, 167, 533.

[82] C. Langham, P. Piaggio, D. Bethell, D. F. Lee, P. McMorn, P. C. B. Page, D. J. Willock, C. Sly, F. E. Hancock, F. King, G. J. Hutchings, Chem. Commun. 1998, 1601.

[83] W. O. Haag, R. M. Lago, P. B. Weisz, Nature 1984, 309, 589.

[84] P. A. Wright, J. M. Thomas, A. K. Cheetham, A. K. Nowak, Nature 1985, 318, 611.

[85] E. G. Derouane, D. J. van der Veken, Applied Catalysis 1988, 45, L15.

[86] J. M. Thomas, Angew. Chem.-Int. Edit. Engl. 1994, 33, 913.

[87] R. A. van Santen, Cat. Tech., 1998, 2, 161

[88] R. Raja, P. Ratnasamy, J. Mol. Cat., 1995, 100, 93

[89] S. O. Lee, G. Sankar, S. J. Kitchin, M. Dugal, J. M. Thomas, K. D. M. Harris, Catal. Lett. 2001, 73, 91.

[90] S. O. Lee, S. J. Kitchin, K. D. M. Harris, G. Sankar, M. Dugal, J. M. Thomas, J. Phys. Chem. B 2002, 106, 1322.

[91] H. van Bekkum, E. M. Flanigan, J. C. Jansen eds. Introduction to Zeolite Science and Practice, Elsevier, Amsterdam, 1991, and references therein

[92] A. K. Cheetham, G. Ferey, T. Loiseau, Angew. Chem.-Int. Edit. 1999, 38, 3269.

[93] J. M. Thomas, G. A. Somorjai, Top. Catal. 1999, 8, U1.

[94] (a) J. M. Thomas, G. N. Greaves, Science 1994, 265, 1675; (b) J. M. Thomas, Chem.-Eur. J. 1997, 3, 1557.

[95] (a) R. Raja, P. Ratnasamy, Stud. Surf. Sci. Catal. 1996, 101, 181; (b) see also M. 
Eswaramoorthy, Neeraj, C.N.R. Rao, Chem. Commun. 1998, 615.

[96] R. Raja, P. Ratnasamy, Stud. Surf. Sci. Catal. 1997, 105, 1037.

[97] R. Raja, P. Ratnasamy, J. Catal. 1997, 170, 244.

[98] J.M. Thomas, R. Raja, Chem. Rec. 2001, 1, 448.

[99] N. Herron, C. A. Tolman, J. Am. Chem. Soc. 1987, 109, 2837.

[100] J. M. Thomas, R. Raja, Chem. Commun. 2001, 675.

[101] R. Raja, G. Sankar, J. M. Thomas, Angew. Chem.-Int. Edit. 2000, 39, 2313.

[102] J. M. Thomas, R. Raja, G. Sankar, R. G. Bell, D. W. Lewis, Pure Appl. Chem. 2001, 73, 1087.

[103] J. M. Thomas, R. Raja, G. Sankar, B. F. G. Johnson, D. W. Lewis, Chem.-Eur. J. 2001, 7, 2973.

[104] K. Sato, M. Aoki, R. Noyori, Science 1998, 281, 1646.

[105] S. O. Lee, R. Raja, K. D. M. Harris, J. M. Thomas, B. F. G. Johnson, G. Sankar, Angew. Chem.-Int. Edit. 2003, 42, 1520.

[106] Biocatalytic conversion of starch yields cis,cis muconic acid. Our test experiments (reported in ref. 106(b) for convenience employed the more readily (commercially) available trans,trans variant. (a) K. M. Draths, J.W. Frost, J. Am. Chem. Soc. 1994, 116, 399; (b) J. M. Thomas, R. Raja, B. F. G. Johnson, T. J. O’Connell, G. Sankar, T. Khimyak, Chem. Commun. 2003, 1126. See also "Editor's Choice", Science, 2003, 300, 867.

[107] L. J. Burcham, L. E. Briand, I. E. Wachs, Langmuir 2001, 17, 6164.

[108] R. Noyori, M. Aoki, K. Sato, Chem. Commun. 2003, 1977.

[109] I. J. Shannon, T. Maschmeyer, R. D. Oldroyd, G. Sankar, J. M. Thomas, H. Pernot, J. P. Balikdjian, M. Che, J. Chem. Soc. Faraday Trans. 1998, 94, 1495.

[110] R. Murugavel, H. W. Roesky, Angew. Chem. Int. Ed. Engl. 1997, 36, 477.

[111] M. Guidotti, N. Ravasio, R. Psaro, E. Gianotti, L. Marchese, S. Coluccia, Green Chem. 2003, 5, 421.

[112] N. Ravasio, F. Zaccheria, M. Guidotti, R. Psaro, Top. Catal. 2004, 27, 157.

[113] D. H. Olson, W. M. Meier, Atlas of Zeolite Strutures, Elsevier, Ámsterdam, 2003

[114] (a) P. Ratnasamy, D. Srinivas, H. Knözinger, Advances in Catalysis, 2004, 48, 1; (b) J. M. Thomas, K. I. Zamaraev, Angew. Chem. Int. Ed. Engl. 1994, 33, 308

[115] It is recognized that, so far as TS-1 is concerned, this catalyst works best in selective oxidation when $\mathrm{H}_{2} \mathrm{O}_{2}$ is the oxidant. On the other hand, the $\mathrm{Ti} / \mathrm{SiO}_{2}$ catalysts for epoxidation studied by us, Ravasio et al., and others functions best with an alkylhydroperoxide as oxidant. (a) J. M. Thomas, C. R. A. Catlow, G. Sankar, Chem. Commun. 2002, 2921; (b) C. R. A. Catlow, S. A. French, A. A. Sokol, J. M. Thomas, Phil. Trans. Roy. Soc. A, 2005, in press.

[116] M. Fujiwara, H. Wessel, P. Hyung-Suh, H. W. Roesky, Tetrahedron 2002, 58, 239.

[117] J. M. Thomas, G. Sankar, M. C. Klunduk, M. P. Attfield, T. Maschmeyer, B. F. G. Johnson, R. G. Bell, J. Phys. Chem. B 1999, 103, 8809.

[118] R. Raja, J. M. Thomas, Proc. 13 ${ }^{\text {th }}$ Intl. Congr. Catalysis, Paris, 2004, P5 103.

[119] (a) R. Raja, J. M. Thomas, G. Sankar, Chem. Commun. 1999, 525; (b) see also G. Strukul, Angew. Chem. Int. Ed. 1998, 37, 1198.

[120] H. Oevering, R. Raja, H. Wolters, W. Buijs, J. M. Thomas, Process for the production of an oxime from a ketone or aldehyde, European Patent Filing No. EP 03078997, 2003.

[121] G. G. Hlatky, Chem. Rev. 2000, 100, 1347.

[122] D. E. de Vos, I. F. J. Vankelecom, P. A. Jacobs (eds), Chiral Catalyst Immobilization and Recycling, Wiley-VCH, Weinheim, 2000

[123] P. McMorn, G. J. Hutchings, Chem. Soc. Rev. 2004, 33, 108.

[124] C. Bianchini, P. Barbaro, V. Dal Santo, R. Gobetto, A. Meli, W. Oberhauser, R. Psaro, F. Vizza, Adv. Synth. Catal. 2001, 343, 41 and references therein

[125] (a) M. J. Sabater, A. Corma, A. Domenech, V. Fornes, H. Garcia, Chem. Commun. 1997, 1285; (b) 
A. Corma, H. Garcia, Chem. Rev. 2002, 102, 3837; (c) A. Corma, H. Garcia, Chem. Rev. 2003, 103, 4307.

[126] S. Xiang, Y. L. Zhang, Q. Xin, C. Li, Angew. Chem. Int. Ed. 2002, 41, 821.

[127] (a) B. M. L. Dioos, W. A. Geurts, P. A. Jacobs, Catal. Lett. 2004, 97, 125; (b) C. Simons, U. Hanefeld, I. W. C. E. Arends, A. J. Minnaard, T. Maschmeyer, R. A. Sheldon, Chem. Commun. 2004, 2830; (c) M. van den Berg, A. J. Minnaard, E.P. Schudde, J. van Esch, A. H. M. de Vries, J. G. de Vries, B. L. Feringa, J. Am. Chem. Soc. 2000, 122, 11539.

[128] (a) R. Raja, J.M. Thomas, M.D. Jones, B.F.G. Johnson, Process for reducing ketocarboxylic esters, German Patent Filing No. DE 1030 5946, 2003; (b) R. Raja, J.M. Thomas, M.D. Jones, B.F.G. Johnson, Process for preparing enantiomerically enriched ((- hydroxycarboxylic esters, German Patent Filing No. DE 1030 5943, 2003.

[129] R. Raja, J.M. Thomas, M.D. Jones, B.F.G. Johnson, Process for asymmetrically hydrogenating ketocarboxylic esters, US Patent Filing No. US 10326915, 2004.

[130] R. Raja, J.M. Thomas, M.D. Jones, B.F.G. Johnson, Verfahren zur asymmetrischen hydrierung von ketocarbonsäureestern, European Patent Filing No. EP 4001904, 2004.

[131] J. M. Thomas, Sci.Am. 1992, 266, 112.

[132] (a) W. Hölderich, New Frontiers in Catalysis, Elsevier, Amsterdam, 1992, pp. 145-150; (b) A. Corma, Chem. Rev. 1997, 97, 2373; (c) K. Hedden, J. Weitkamp, Chem-Ing-Tech. 1983, 55, 907; (d) P. B. Weisz, Pure Appl. Chem. 1980, 52, 99.

[133] R. A. van Santen, P. W. N. M. can Leeuwen, J. A. Moulijn, B. A. Avenill, Catalysis: An Integrated Approach, 2nd Edition, 2000, Netherlands Institute of Catalysis Research

[134] J. M. Thomas, W. J. Thomas, Heterogeneous Catalysis: Principles and Practice, Wiley-VCH, Weinheim, Chapter No. 8, 1997.

[135] I. Chorkendorff, J. W. Niemantsverdriet, Concepts in Modern Catalysis and Kinetics, Wiley-VCH, 2003, p365 et seq

[136] C. S. John, D. M. Clark, I. E. Maxwell, in Perspectives in Catalysis, (J. M. Thomas, K. I. Zamaraev eds.), Blackwell Sci. Pubs., Oxford, 1992, p387

[137] Smith et al ${ }^{138}$ showed that nitration of halogenobenzene using the $\mathrm{H}^{+}$form of zeolite beta ( $\mathrm{Si} / \mathrm{Al}$ ratio 25) as a catalyst and a combination of liquid $\mathrm{N}_{2} \mathrm{O}_{4}$ and gaseous $\mathrm{O}_{2}$ as the nitrating agents lead to high yields and significant para- selectivity (e.g. 85:15 para:ortho)

[138] K. Smith, S. Almeer, S. J. Black, Chem. Commun. 2000, 1571.

[139] M. Nowotny, T. Maschmeyer, B.F.G. Johnson, P. Lahuerta, J.M. Thomas, J.E. Davies, Angew. Chem. Int. Ed. 2001, 40, 955.

[140] C. Copéret, F. Lefebvre, J.M. Basset, in Handbook of Metathesis, (R.H. Grubbs ed.), Wiley-VCH, Weinheim, 2003, Vol. 1, p. 190.

[141] L. Lefort, M. Chabanas, O. Maury, D. Meunier, C. Copéret, J. Thivolle-Cazat, J.M. Basset, J. Organomet. Chem. 2000, 594, 96.

[142] M. W. McKittrick, C. W. Jones, Chem. Mat. 2003, 15, 1132.

[143] S. Bordiga, G. Ricchiardi, G. Spoto, D. Scarano, L. Carnelli, A. Zecchina, C.O. Areán, J. Chem. Soc. Faraday Trans. 1993, 89, 1843.

[144] C.K. Chiang, C.R. Fisher, Y.W. Park, A.J. Heeger, H. Shirakawa, E.J. Louis, S.C. Gau, A.G. MacDiarmid, Phys. Rev. Lett. 1977, 39, 1098.

[145] K. Yamaguchi, K. Mori, T. Mizugaki, K. Ebitani, K. Kaneda, J. Am. Chem. Soc. 2000, 122, 7144. 


\section{Legends for Figures and Tables}

\begin{tabular}{|c|c|c|}
\hline & & $\begin{array}{l}\text { A temperature-programmed spectrum shows three peaks } \\
\text { corresponding to progressively stronger bound states at terrace, } \\
\text { step and kink sites of an adsorbate molecule } \\
\text { (methylcyclohexanone) at a roughened Cu surface. [1] }\end{array}$ \\
\hline Fig. 1 & $\mathrm{~B}$ & $\begin{array}{l}\text { Even on a flat surface, such as the (111) face of Pt, there are } \\
\text { three distinct sites for a molecule such as co to be adsorbed. }\end{array}$ \\
\hline Fig. 1 & $\mathrm{C}$ & $\begin{array}{l}\text { The decline in the heat of adsorption with increasing coverage } \\
\text { of a flat single-crystal surface arises because of the } \\
\text { heterogeneity of sites and mutual repulsion of species adsorbed } \\
\text { |at neighboring sites. [2] }\end{array}$ \\
\hline Fig. 2 & A & $\begin{array}{l}\text { Silsesquioxanes \{general formula (RSiO1.5) n are structurally } \\
\text { |similar to (-cristobalite and (-tridymite. They are, } \\
\text { |effectively, soluble analogues of silica; and a heteroatom } \\
\text { (usually transition metal or Ge) attached to the silsesquioxane } \\
\text { |simulates the behavior (in solution) of the same, grafted atom } \\
\text { |attached to mesoporous silica forming the corresponding } \\
\text { heterogeneous catalyst. Figure 2A shows structure of Cy8si8012 } \\
\text { (Cy = cyclohexyl). }\end{array}$ \\
\hline Fig. 2 & $\mathrm{~B}$ & $\begin{array}{l}\text { Fragment of the crystal structure (schematic) of a } \\
\text { TilV-cyclopentadienyl complex bound to two silsesquioxane } \\
\text { moieties (after F.T. Edelmann et al., J. Organomet. Chem. 2001, } \\
620,80) \text {. }\end{array}$ \\
\hline Fig. 2 & $\mathrm{C}$ & $\begin{array}{l}\text { Actual structure (shown in B), indicating the isolated nature of } \\
\text { |the TiIV center (Hydrogen atoms have been omitted for clarity). }\end{array}$ \\
\hline Fig. 2 & $\mathrm{D}$ & |A soluble Brönsted acid site formed from silsesquioxanes. [15 b] \\
\hline Fig. 3 & & $\begin{array}{l}\text { An isolated site, such as a tripodally bound zirconium hydride } \\
\text { |at a silica surface, readily activates methane at modest } \\
\text { temperatures.[20] }\end{array}$ \\
\hline Fig. 4 & A & $\begin{array}{l}\text { A high-resolution electron micrograph of an ordered mesoporous } \\
\text { silica where the diameter of the pores is ca } 100 \AA \text { and the walls } \\
\text { are only a few atoms thick. }\end{array}$ \\
\hline Fig. 4 & B & $\begin{array}{l}\text { Each pore is lined with pendant silanol (?Si(OH) groups [yellow } \\
\text { |= silicon; red = oxygen; white = hydrogen]. }\end{array}$ \\
\hline Fig. 5 & & $\begin{array}{l}\text { Experimentally, by in situ measurements, [27a] the course of } \\
\text { conversion of a free titanocene dichloride molecule (top right) } \\
\text { into a tripodally bound isolated site of ?Ti(OH (bottom right) } \\
\text { may be followed by X-ray absorption spectroscopy. [28] Note the } \\
\text { pronounced 'pre-edge' peak signifying 4-coordinated TiIV (at } \\
\text { |bottom left) of the XANES spectra. Bond distances are extracted } \\
\text { from EXAFS spectra, whilst the energetics are from DFT } \\
\text { |calculations.[27b] }\end{array}$ \\
\hline Fig. 6 & & $\begin{array}{l}\text { The "half-sandwich" surface intermediate (see middle left of } \\
\text { Figure 5), with the van der Waals envelope surrounding the } \\
\text { |cyclopentadienyl ligands ensures that only spatially isolated, } \\
\text { |tripodal TiIV sites are formed in this procedure. EXAFS data } \\
\text { show the absence of Ti(O(Ti linkages. }\end{array}$ \\
\hline Fig. 7 & & $\begin{array}{l}\text { The Tilley method }[32,33] \text { of preparing single-site catalysts on } \\
\text { mesoporous silica via thermolytic molecular precursors such as } \\
\text { |M[OSi (OtBu) 3]n. }\end{array}$ \\
\hline Fig. 8 & & $\begin{array}{l}\text { An isolated atom of Pd (black) when bound (by charge-transfer) } \\
\text { to an F-center at the surface of Mgo forms [36] the stable } \\
\text { complex Pd(CO) } 202 \text { - see text. } \\
\text { (a) Computationally-optimized structure of the }\end{array}$ \\
\hline
\end{tabular}




\begin{tabular}{|c|c|}
\hline & $\begin{array}{l}\text { MgO(Fe)-Pd-(CO) } 202 \text { complex. [36] (b), (c) selected } \\
\text { configurations, and (d) the potential energy versus time, } \\
\text { recorded in an ab initio MD simulation where co2 is formed from } \\
\text { the complex shown in (a). The simulation starts[37] from the } \\
\text { transition state shown in (b). The potential energy of the } \\
\text { transition state is } 0.84 \mathrm{eV} \text { above the optimized configuration } \\
\text { shown in (a). (c), a snapshot at } 210 \mathrm{fs,} \mathrm{where} \mathrm{the} \mathrm{formed} \mathrm{CO2} \\
\text { is desorbing and the remaining O atom from o2 is moving towards } \\
\text { the F-center. [Pd = black; Mg and O ions of Mgo are blue and } \\
\text { red; adsorbed o2 is yellow; carbons are gray and their } \\
\text { respective oxygens are purple and green]. }\end{array}$ \\
\hline Fig. 10 & $\begin{array}{l}\text { Single-site active centers designed by Basset et al[20] for } \\
\text { heterogeneously catalyzed metathesis reactions. }\end{array}$ \\
\hline Fig. 11 & $\begin{array}{l}\text { Non-covalently bound } \mathrm{Rh}(\mathrm{I}) \text { centred molecular complex for } \\
\text { hydroformylation (left) immobilized at a silica surface. The } \\
\text { species on the right is catalytically inactive, and it forms on } \\
\text { prolonged exposure of the one on the left to syngas. [42] }\end{array}$ \\
\hline Fig. 12 & $\begin{array}{l}\text { Top right, a mixed-metal cluster carbonylate } \\
\text { [Rul2Cu4C2 (CO) 32Cl2]2- is readily sequestered within the } \\
\text { mesopores of silica in the presence of the molecular cation PPN+ } \\
\text { (bis (triphenylphosphane) iminium). The carbonyls are held by } \\
\text { hydrogen-bonds (bottom right) to the silanol-rich inner surface. } \\
\text { Upon gentle thermolysis, all the organic components are } \\
\text { eliminated (as judged by in situ FTIR) leaving mono-disperse } \\
\text { mixed metal (Rul2Cu4C2) clusters within the mesopores. Top } \\
\text { left, individual mixed-metal clusters (shown in red) anchored } \\
\text { inside pores (average diameter ca } 35 \AA \text { ) of the silica support. } \\
\text { Bottom left, another high-resolution electron micrograph, where } \\
\text { each white spot denotes a single mixed-metal cluster. [51] }\end{array}$ \\
\hline Fig. 13 & $\begin{array}{l}\text { An axial projection of a } 30 \mathrm{~nm} \text { thick specimen and five } \\
\text { successive } 3 \mathrm{~nm} \text { thick slices through a scanning electron } \\
\text { tomogram[52] of silica-supported Rulopt } 2 \mathrm{c} 2 \text {. (Nanoparticles } \\
\text { shown in red, mesoporous silica, white). }\end{array}$ \\
\hline Fig. 14 & $\begin{array}{l}\text { EXAFS analysis[49] yields the structural information shown on } \\
\text { left of the Ru12Cu4C2 nanoparticle hydrogenation catalyst. The } \\
\text { structural information on the right was deduced from a combined } \\
\text { EXAFS-DFT approach [see S. Bromley et al. Chem. Phys. Lett. } \\
2001,340,524 \text { ]. }\end{array}$ \\
\hline Fig. 15 & $\begin{array}{l}\text { Sequence of steps illustrating how the exterior surface of the } \\
\text { mesoporous silica support is rendered inactive and hydrophobic } \\
\text { by covalent attachment of Si(Ph) } 2 \text { groups. [49] Only the silanol } \\
\text { groups at the inner surfaces are implicated in the support of } \\
\text { the nanoparticles (compare Figure 12). }\end{array}$ \\
\hline Fig. 16 & $\begin{array}{l}\text { Two distinct approaches may be used[49] to introduce an anchored } \\
\text { chiral (asymmetric) organometallic inside the mesopores. }\end{array}$ \\
\hline Fig. 17 & $\begin{array}{l}\text { Illustration (to scale) of how a spatial constraint is imposed } \\
\text { on the asymmetric catalyst when it is anchored at a concave } \\
\text { surface (A) in contrast to the situation when anchored at a } \\
\text { convex one (B). The catalytic performance (selectivity and ee } \\
\text { in the hydrogenation of E-(()-phenylcinnamic acid) of an } \\
\text { asymmetric catalyst in greater in A than in } B \text {, as summarized in } \\
\text { C. [57] }\end{array}$ \\
\hline Fig. 18 & $\begin{array}{l}\text { A triflate counter-ion, which is strongly hydrogen-bonded to the } \\
\text { silanols of the silica, holds securely (by ionic forces) the } \\
\text { chiral organometallic RhI-centred cation. [44] }\end{array}$ \\
\hline Fig. 19 & Views of three examples of "ship-in-bottle" SSHCs. (a) \\
\hline
\end{tabular}




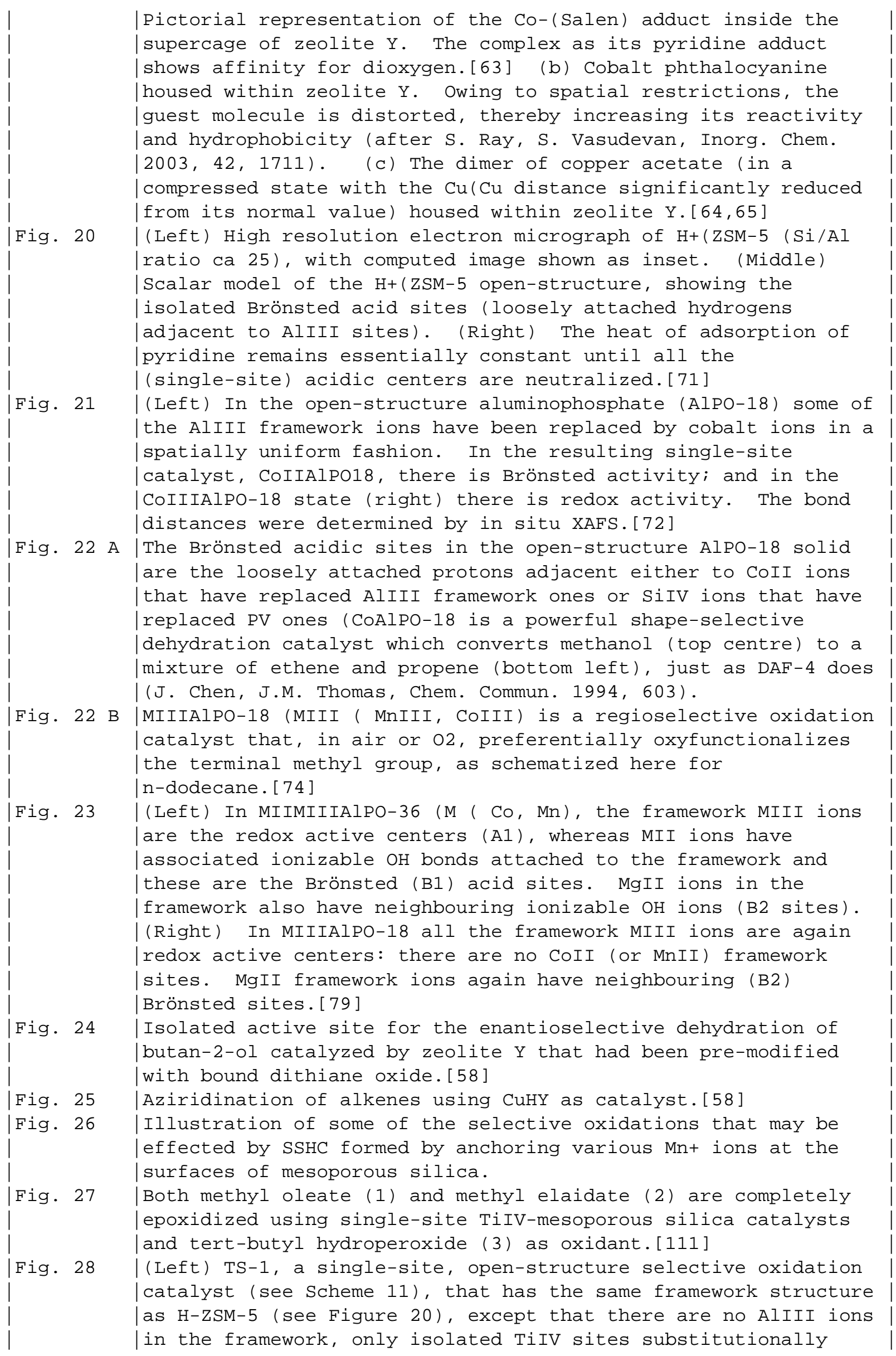




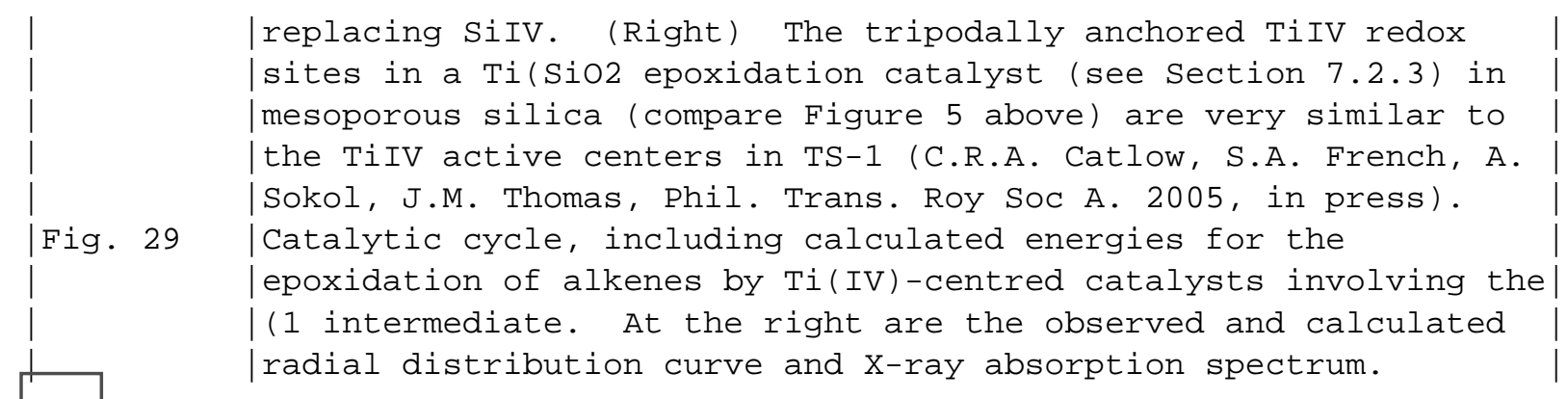

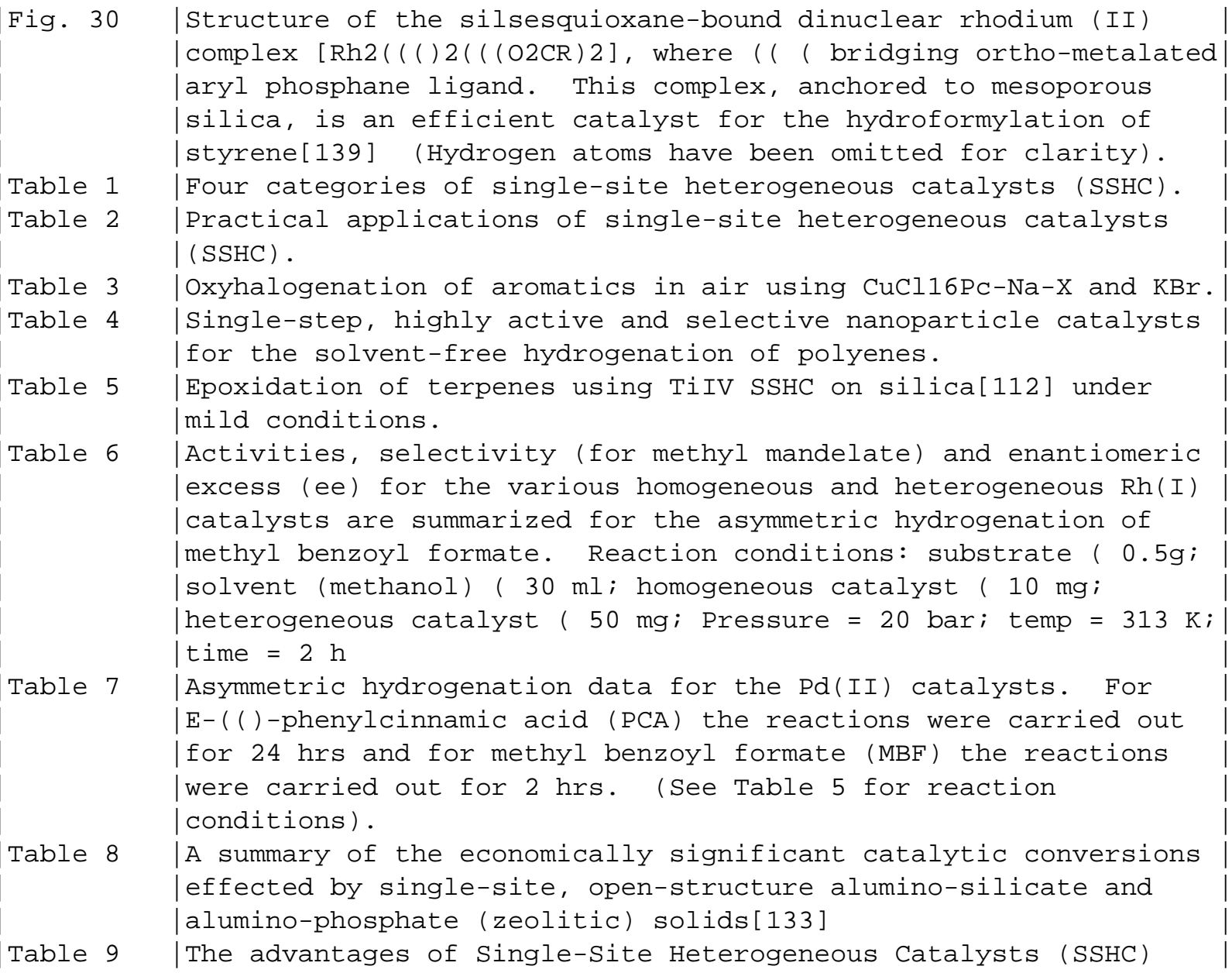

$†$ Based on the Sunner Memorial Lecture given (by JMT) at Lund University, November 1, 2004. 